\title{
Distribution Pattern of Soil Organic Carbon and Its Regional Humification Constant in the Coastal Monsoon Region of Eastern China
}

\section{Shutian Liu}

Nanning Normal University

Xiansheng Xie

Nanning Normal University

Xiaochuan Wang

Nanning Normal University

Xinxin Feng

Nanning Normal University

Xianda Hou

Nanning Normal University

Shuojin Wang

Nanning Normal University

Keyu Lin

Nanning Normal University

Mei Huang

Nanning Normal University

Shugang Jia

Nanning Normal University

Yanlin Hou (D2483977138@qq.com )

Nanning Normal University

\section{Sen Dou}

Jilin Agricultural University

\section{Research Article}

Keywords: Eastern coast, SOC, Annual average temperature, Annual average precipitation, Model

Posted Date: May 18th, 2021

DOI: https://doi.org/10.21203/rs.3.rs-445815/v1 
License: (c) (i) This work is licensed under a Creative Commons Attribution 4.0 International License. Read Full License 

humification constant in the coastal monsoon region of eastern China

Shutian Liu ${ }^{1,2,3, \#}$ \& Xiansheng Xie ${ }^{1,2,3, \#}$ \& Xiaochuan Wang ${ }^{1,2,3}$ \& Xinxin Feng ${ }^{1,2,3}$ \& Xianda Hou ${ }^{1,2,3}$ \& Shuojin Wang ${ }^{1,2,3}$ \& Keyu Lin ${ }^{1,2,3}$ \& Mei Huang ${ }^{1,2,3}$ \& Shugang Jia ${ }^{1,2,3}$ \& Yanlin Hou ${ }^{1,2,3,}$ \& Sen Dou ${ }^{4}$

6

\author{
${ }^{1}$ Guangxi Geographical Indication Crops Research Centre of Big Data Mining and Experimental Engineering Technology, \\ Nanning Normal University, Nanning 530001, China; \\ ${ }^{2}$ Guangxi Key Laboratory of Earth Surface Processes and Intelligent Simulation, Nanning Normal University, Nanning \\ 530001, China; \\ ${ }^{3}$ School of Geography and Planning, Nanning Normal University, Nanning 530001, China; \\ ${ }^{4}$ College of Resource and Environmental Science, Jilin Agricultural University, Changchun 130118, China \\ \#Joint first authors \\ *Corresponding author, e-mail: 2483977138@qq.com; dousen1959@126.com \\ (Received; accepted )
}

\begin{abstract}
Soils are an important pool for storing organic carbon. Soil organic carbon (SOC) content is generally considered as an important indicator to evaluate farmland soil quality. The loss of SOC causes soil degradation and reduces the sustainability of farmland. In order to reveal the distribution pattern of SOC in the coastal monsoon area of eastern China, and to clarify the macro dominant factors of SOC accumulation caused by temperature and precipitation, this paper analyzed the distribution pattern of SOC in the coastal monsoon area of eastern China by using the SOC data collected from the national soil testing and formula fertilization data set, and discussed the effects of temperature and precipitation on SOC content. According to the provincial administrative divisions, the distribution of SOC in the coastal monsoon areas of eastern China from Heilongjiang Province to Hainan Province was calculated. According to the annual average temperature $<10.18^{\circ} \mathrm{C}, 10.18{ }^{\circ} \mathrm{C} \sim 20.95^{\circ} \mathrm{C},>20.95^{\circ} \mathrm{C}$, annual average precipitation $0 \sim 400 \mathrm{~mm}$, $400 \sim 800 \mathrm{~mm},>800 \mathrm{~mm}$, the study area was divided into different regions, and the effects of annual average temperature and annual average precipitation on SOC content were studied. In the region with annual average temperature less than $10.18^{\circ} \mathrm{C}$, the temperature had a negative correlation with the accumulation of organic carbon, and the ratio of precipitation and temperature had a positive correlation with the accumulation of SOC; In the region of $10.18^{\circ} \mathrm{C} \sim 20.95^{\circ} \mathrm{C}$, the annual average temperature and annual average precipitation had a significant positive correlation, and the ratio of precipitation and temperature had a positive correlation with the accumulation of SOC; In the region $>20.95^{\circ} \mathrm{C}$, the temperature had a negative correlation with the accumulation of organic carbon, and the ratio of precipitation and temperature was not related to the accumulation of SOC. In the range of $0 \sim 400 \mathrm{~mm}$ of annual average precipitation, the temperature had a positive correlation with the accumulation of SOC, and the ratio of precipitation and temperature had a negative correlation with the accumulation of SOC; In the range of $400 \sim 800 \mathrm{~mm}$ of annual average precipitation, the temperature had a negative correlation with the accumulation of SOC, and the ratio of precipitation and temperature had a positive correlation with the accumulation of SOC; In the region $>800 \mathrm{~mm}$ of annual average precipitation, the temperature had a positive correlation with the accumulation of organic carbon before the annual average temperature of $20.95^{\circ} \mathrm{C}$, and after the annual average temperature of $20.95^{\circ} \mathrm{C}$, the temperature had a negative correlation with the accumulation of organic carbon, and the ratio of precipitation and temperature had no significant effect on the accumulation of SOC. On the macro scale, the annual average temperature and precipitation had significant effects on the distribution pattern of SOC in the coastal monsoon area of eastern China. According to the influence of annual average temperature and annual average precipitation on SOC accumulation, a comprehensive model based on the annual average temperature and annual average precipitation on SOC accumulation is established. Through regression verification of the model, the correlation coefficient, $\mathrm{r}=0.999{ }^{* *}$, the cubic curve equation could better simulated the relationship between the predicted value and the real value of SOC, $\mathrm{r}=0.7048^{* *}$, the model can reflect the cumulative effect of annual average temperature and annual average precipitation on SOC accumulation Combined with the impact.
\end{abstract}

Keywords: Eastern coast, SOC, Annual average temperature, Annual average precipitation, Model 


\section{Introduction}

As one of the main terrestrial carbon pools, global climate change has an important impact on soil carbon pool. SOC has been widely studied as a key determinant of regional food security and global food crisis warming (Diel and Franko, 2020; Nave et al., 2018). Due to the long-term cultivation of human beings, the physical and chemical properties of soil change, which accelerates the decomposition of mineral and soil organic matter, and ultimately leads to the loss of soil productivity (Padilha et al., 2020). Especially in the global warming environment, some scholars expect to accelerate the decomposition and transformation of SOC, but the decomposition rate of SOC is not clear (Yan et al., 2017). Some studies have shown that the impact of precipitation on s SOC is mainly produced by changing the function and structure of terrestrial ecosystem, because water is the basic driving force of almost all chemical and biological processes, including plant growth and survival (Gong et al., 2020), photosynthesis (Hui et al., 2018), and microbial activity (Ma et al., 2020) and soil respiration (Wu et al., 2020). Within tolerable limits, the biological processes that promote the decomposition of organic carbon will be faster at higher temperatures, with an average rainfall of $1750 \mathrm{~mm}$ to $2500 \mathrm{~mm}$, and the SOC storage is relatively small (Vitharana et al., 2019).

At the regional scale, the effect of precipitation on microbial metabolic limitation strongly restricts the stability of SOC. With the increase of precipitation, the increase of SOC decomposition rate may be the result of the increase of microbial nutrition limitation (Cui et al., 2019). However, some scholars believe that at the regional scale, soil physical and chemical properties and terrain factors may be greater than the dynamic impact of climatic factors on SOC. Soil $\mathrm{pH}$ value is the key control factor of SOC dynamic change, temperature and humidity are the secondary driving forces of SOC dynamics at regional scale (Xu et al., 2019). The spatial variation of temperature is often used to characterize the effect of temperature on SOC storage at current and warmer temperatures (Abramoff et al., 2019). There is a complex relationship between the intrinsic temperature sensitivity and the apparent temperature sensitivity of organic carbon decomposition. This relationship is not only controlled by the molecular / chemical composition of organic carbon pool, but also by the critical temperature of organic carbon decomposition (Dash et al., 2019). The balance of organic carbon in farmland soil depends on how crop and soil management measures affect biomass carbon input and soil carbon loss through organic matter decomposition and erosion (Ghimire et al., 2019). Soil tillage often leads to the loss of agricultural SOC, because agricultural activities increase soil biological activity and bring organic residues in contact with decomposers.

Since the mid-20th century, many scholars have established SOC models. After decades of research, many SOC simulation models have been established. Among them, century, Roth C and DNDC models are widely used. Century model was first used to simulate soil organic matter in grassland ecosystem (Li et al., 2016). Later, it was applied to the farmland (Sakrabani and Hollis, 2018) and wetland (Ouyang et al., 2014) and other ecosystems, and got good simulation and prediction results. The Roth $\mathrm{C}$ model can better simulate the trend of farmland SOC (Senapati et al., 2014). The structure of the model is relatively simple. It only considers the process of organic carbon in the soil, does not consider the plant growth process, and does not consider the amount of organic carbon that plants or crops enter into the soil. The DNDC model can simulate the biochemical processes of carbon (Zhang et al., 2017; Li et al., 2016) and nitrogen (Jiang et al., 2019), as well as denitrification and decomposition processes (Gilhespy et al., 2014), and the prediction intensity of the model is very high (Khalil et al., 2019). However, different land use types lead to significant changes in SOC concentration and chemical structure, thus affecting the absorption and dynamic cycle of soil carbon in the ecosystem (Bhattacharyya et al., 2020).

Woolf et al. (2019) applied the microbial based organic carbon model to predict SOC, and the predicted results were consistent with the global organic carbon distribution. Laub et al. (2018) proposed a "mixed model over continuous depth" (mmcd), which uses linear and quadratic terms to simulate the change of soil properties with depth, and predicts the spatial distribution of soil properties at the landscape level, the prediction interval (95\%) accurately covers the range of residual measurements. In recent years, with the application of hyperspectral technology, some scholars use it to predict SOC. Gu et al. (2019) hyperspectral inversion of SOC content in cultivated land was carried out based on wavelet transform, and the prediction accuracy of SOC content was effectively improved by using the model. Guo et al. (2019) used laboratory spectral data and aerial hyperspectral images to predict SOC storage. They could successfully predicted SOC storage through direct and indirect methods. Yang et al. (2020) extracted phenological parameters from normalized difference vegetation index (NDVI) time series data and combined them with crop rotation to predict the SOC content of a farmland in Anhui Province. Rotation and two phenological parameters were added to the natural environment variables, which greatly improved the prediction accuracy. Yang et al. (2019) used the information of direct rotation and the variables generated by Fourier transform to capture the periodic effect of crop rotation. The results showed that the combination accuracy of natural 
109

environment variables, rotation type and Fourier transform variables was the highest. Adi et al. (2020) used linear regression and potential variable model to study the integration of mixed soil environmental data sets, the proposed 2-Step-R technology could better predicted SOC model.

In terms of the current methods for studying the prediction models of organic carbon, the main influencing factors and control process of SOC distribution are still poorly understood at the macro scale, which is an important reason for the emergence of unknown carbon sink, prediction of climate change and its impact uncertainty. Climate, soil texture and management time are the main driving factors of SOC change (Liang et al., 2020). Temperature and precipitation simultaneously affect SOC content in agricultural ecosystems. Although individual effects of these parameters have been widely studied, their comprehensive effects are still poorly understood in the regional scope (Felton et al., 2020).

Mainland China extends from South Asia to East Asia, forming a large area (Chang et al., 2019) affected by the Asian monsoon. In the eastern monsoon region of China, the spatial and temporal distribution of precipitation is extremely uneven (Xia et al., 2017). Especially in summer, the water vapor in the East China monsoon region (ECMR) mainly comes from low latitude areas and is affected by the activities of East Asian tropical cyclone (Lin et al., 2017). The results show that the East Asian summer monsoon is significantly sensitive to the moist soil in the Yangtze River Delta (Zuo and Zhang et al., 2016). Moreover, in the 21st century, there is an East Asian summer monsoon in eastern China, and the climate is unstable (Ma et al., 2019). But basically, the distribution of drought and flood in the south of China is opposite to that in other regions. The distribution of drought and flood in the Yellow River Basin and Huaihe River Basin is opposite to that of the Yangtze River Basin and its southern region, while the distribution of drought and flood in the East is opposite to that in the West (Li et al., 2011).

This paper uses SOC data from China's latest soil test and formula fertilization data set, and combined with the meteorological data of China Meteorological science data sharing service network for analysis. The range of meteorological data spans more than 5,000 kilometers along the southeast coast of China. On a global scale, revealing the influence of annual average accumulated temperature and annual average precipitation on SOC content is helpful to clarify the macro-leading factors of SOC distribution. Under the background of global warming, we study the correlation between soil organic carbon and annual mean accumulated temperature and precipitation at or above $10^{\circ} \mathrm{C}$. It provides a scientific basis for formulating farmland soil management policies, promoting soil carbon sequestration and reducing carbon losses.

\section{Materials and methods}

\section{Study site}

This study covers 13 Provinces (autonomous regions and municipalities) in the southeast coastal monsoon region of China, including Heilongjiang Province, Jilin Province, Liaoning Province, Beijing City, Tianjin city, Hebei Province, Shandong Province, Jiangsu Province, Shanghai City, Zhejiang Province, Fujian Province, Guangdong Province and Hainan Province. Jilin and Heilongjiang Provinces close to the sea of Japan. The main soil types in each study area are shown in Table 1, and the distribution of sample points is shown in Figure 1.

Table 1. Main soil types in the study area

\begin{tabular}{|c|c|c|c|}
\hline $\begin{array}{c}\text { Provinces } \\
\text { (municipalities) }\end{array}$ & main soil types & $\begin{array}{c}\text { Provinces } \\
\text { (municipalities) }\end{array}$ & main soil types \\
\hline Heilongjiang Province & $\begin{array}{l}\text { black soil, albic soil, } \\
\text { meadow soil, swamp soil }\end{array}$ & Jilin Province & $\begin{array}{l}\text { black soil, meadow soil, } \\
\text { chernozem }\end{array}$ \\
\hline Liaoning Province & meadow soil, tidal soil & Hebei Province & $\begin{array}{l}\text { cinnamon soil, fluvo soil, } \\
\text { brown soil }\end{array}$ \\
\hline Beijing City & $\begin{array}{l}\text { cinnamon soil, fluvo soil, } \\
\text { brown soil }\end{array}$ & Tianjin city & $\begin{array}{l}\text { tidal soil, coastal saline } \\
\text { soil, cinnamon soil }\end{array}$ \\
\hline Shandong Province & $\begin{array}{l}\text { brown soil, cinnamon soil, } \\
\text { fluvo soil, Shajiang Black } \\
\text { Soil }\end{array}$ & Jiangsu Province & $\begin{array}{l}\text { paddy soil, fluvo soil, } \\
\text { brown soil, yellow brown } \\
\text { soil }\end{array}$ \\
\hline Shanghai City & $\begin{array}{l}\text { paddy soil, fluvo soil, yellow } \\
\text { brown soil }\end{array}$ & Zhejiang Province & $\begin{array}{l}\text { red soil, paddy soil, coastal } \\
\text { saline soil, fluvo aquic soil }\end{array}$ \\
\hline
\end{tabular}


\begin{tabular}{l|l|l|l} 
Fujian Province & $\begin{array}{l}\text { red soil, yellow soil } \\
\text { Hainan Province }\end{array}$ & $\begin{array}{l}\text { Guangdong } \\
\text { Province } \\
\text { paddy soil }\end{array}$ & $\begin{array}{l}\text { red soil, lateritic red soil, } \\
\text { latosol }\end{array}$ \\
\hline
\end{tabular}

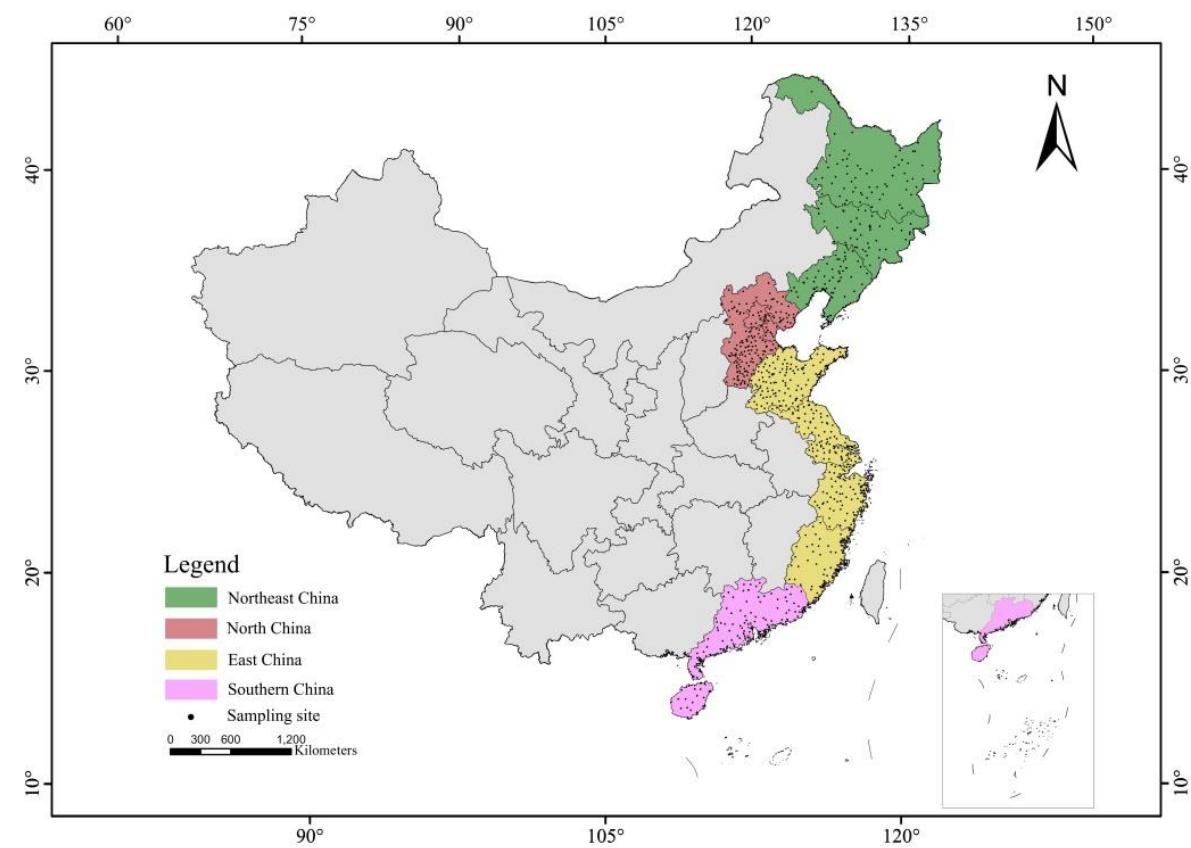

Figure 1. Schematic diagram of the study area and distribution of sample points

\section{Data sources}

The data used in this study comes from the national soil testing and formula fertilization project "Soil Testing and Formula Fertilization Basic Nutrients Data Set (2005-2014)" (National Agricultural Technology Extension Service Centre, 2014), including organic carbon, total nitrogen, Available phosphorus and available potassium indicators. We use the average value of the SOC samples of the county (city, district) as its SOC content, and use the GPS coordinates of the administrative centre as its geographic coordinates.

The meteorological data used in this study mainly included annual average temperature and annual average precipitation, which were from "China Meteorological science data sharing service network" (http://cdc.nmic.cn). The annual average temperature and annual average precipitation data in the climate data mainly used the average value from 2000 to 2016, and the meteorological data of each county (city, district) used the meteorological data of corresponding meteorological observation station. Accumulated temperature $\geq 10^{\circ} \mathrm{C}$ refers to the total temperature when the daily average temperature exceeds or equals to $10^{\circ} \mathrm{C}$. Water temperature ratio $(\mathrm{P} / \mathrm{T})$ refered to the ratio of annual average precipitation to annual average temperature.

\section{Data analysis}

In this study, ArcGIS software was used for semi variance analysis to determine the optimal theoretical semi variance model, and the optimal parameters of Kriging interpolation were obtained. Then spatial interpolation was conducted by geostatistics module of ArcGIS software to obtain the spatial distribution pattern of SOC in the study area. Routine statistical analysis, ANOVA and regression analysis were performed in Excel and SPSS software. Variance analysis was used to reveal whether there were significant differences in the effects of different factors on SOC.

\section{Results}

\section{Distribution pattern of SOC in East China}


It could be seen from Table 2 that from Heilongjiang Province, Jilin Province, Liaoning Province, Beijing City, Tianjin city, Hebei Province, Shandong Province, Jiangsu Province, Shanghai City, Zhejiang Province, Fujian Province, Guangdong Province and Hainan Province, the SOC content tended to decrease first, then increased and then decreased.

The content of SOC in Heilongiiang Province was the highest $\left(19.82 \mathrm{~g} \cdot \mathrm{kg}^{-1}\right)$. With the decrease of latitude, the SOC content in Jilin Province $\left(16.01 \mathrm{~g} \cdot \mathrm{kg}^{-1}\right)$, Liaoning Province $\left(10.22 \mathrm{~g} \cdot \mathrm{kg}^{-1}\right)$, Hebei Province $\left(9.73 \mathrm{~g} \cdot \mathrm{kg}^{-1}\right)$, Tianjin $\left(10.80 \mathrm{~g} \cdot \mathrm{kg}^{-1}\right)$ showed a trend of gradual decrease, and reached the lowest value $(8.08$ $\left.\mathrm{g} \cdot \mathrm{kg}^{-1}\right)$ in Beijing. After that, SOC content increased with the decrease of latitude: from Shandong Province $\left(10.85 \mathrm{~g} \cdot \mathrm{kg}^{-1}\right)$, Jiangsu Province $\left(12.63 \mathrm{~g} \cdot \mathrm{kg}^{-1}\right)$, Shanghai $\left(15.56 \mathrm{~g} \cdot \mathrm{kg}^{-1}\right)$ to Zhejiang Province $\left(16.21 \mathrm{~g} \cdot \mathrm{kg}^{-}\right.$ $\left.{ }^{1}\right)$. However, from Fujian Province $\left(15.32 \mathrm{~g} \cdot \mathrm{kg}^{-1}\right)$, Guangdong Province $\left(13.82 \mathrm{~g} \cdot \mathrm{kg}^{-1}\right)$, to Hainan Province $\left(8.99 \mathrm{~g} \cdot \mathrm{kg}^{-1}\right)$, SOC content showed a downward trend with the decrease of latitude, which was consistent with the trend of organic carbon change with latitude studied by predecessors (Wang et al., 2016).

Table 2. Content of SOC in different Provinces (municipalities)

\begin{tabular}{|c|c|c|c|c|c|c|}
\hline \multicolumn{2}{|c|}{ Provinces/municipality } & $\begin{array}{c}\text { Number of } \\
\text { samples }\end{array}$ & $\begin{array}{l}\text { Max } \\
\text { value }\end{array}$ & $\begin{array}{l}\text { Mini } \\
\text { value }\end{array}$ & $\begin{array}{c}\text { Average } \\
\text { value }\end{array}$ & $\begin{array}{l}\text { Standard } \\
\text { deviation }\end{array}$ \\
\hline \multirow{3}{*}{$\begin{array}{l}\text { Northeast } \\
\text { China }\end{array}$} & $\begin{array}{l}\text { Heilongjiang } \\
\text { Province }\end{array}$ & 67 & 29.84 & 11.45 & 19.70 & 4.17 \\
\hline & Jilin Province & 54 & 33.31 & 7.48 & 16.01 & 6.51 \\
\hline & Liaoning Province & 61 & 18.86 & 5.80 & 10.22 & 3.01 \\
\hline \multirow{3}{*}{$\begin{array}{l}\text { North } \\
\text { China }\end{array}$} & Hebei Province & 166 & 14.85 & 5.13 & 9.68 & 1.89 \\
\hline & Beijing City & 9 & 8.71 & 7.05 & 8.08 & 0.59 \\
\hline & Tianjin city & 10 & 12.42 & 9.51 & 10.80 & 0.94 \\
\hline \multirow{5}{*}{$\begin{array}{l}\text { East } \\
\text { China }\end{array}$} & Shandong Province & 123 & 13.61 & 4.56 & 8.01 & 1.60 \\
\hline & Jiangsu Province & 75 & 20.35 & 7.81 & 12.63 & 2.75 \\
\hline & Shanghai City & 9 & 22.61 & 8.65 & 15.57 & 4.20 \\
\hline & Zhejiang Province & 74 & 20.50 & 9.25 & 16.21 & 2.35 \\
\hline & Fujian Province & 36 & 18.74 & 10.82 & 15.72 & 1.97 \\
\hline \multirow{2}{*}{$\begin{array}{l}\text { South } \\
\text { China }\end{array}$} & Guangdong & 84 & 17.44 & 9.19 & 13.84 & 1.81 \\
\hline & Hainan Province & 12 & 14.98 & 3.67 & 9.83 & 2.91 \\
\hline
\end{tabular}

The northern and eastern areas of Northeast China are northeast forest areas, the northeast forest areas are located in Heilongjiang Province, Jilin Province and Inner Mongolia Autonomous Region, they are mainly composed of the Great Xing'an Mountains, the small Xing'an Mountains and the Changbai Mountains, the eastern Liaoning Province also belonged to the Changbai Mountains (Deng et al., 2018), the total area was 53.5 million hectares, and the forest area was 35.9 million hectares, of which the natural forest area was as high as $91.4 \%$ (Wei et al., 2013). According to Figure 2, the content of SOC was between $5.88 \mathrm{~g} \cdot \mathrm{kg}^{-1} \sim 33.17 \mathrm{~g} \cdot \mathrm{kg}^{-1}$. The average SOC content in Heilongjiang Province was $23.33 \mathrm{~g} \cdot \mathrm{kg}^{-1}$, that in Jilin Province was $16.50 \mathrm{~g} \cdot \mathrm{kg}^{-1}$, and that in Liaoning Province was $10.23 \mathrm{~g} \cdot \mathrm{kg}^{-1}$. The SOC content in the north and east of Northeast China was higher than that in the central and southern regions. The decomposition rate of soil organic matter in warm temperate zone and temperate zone in the south of Northeast China was faster than that in cold temperate zone of North China, and the decomposition rate of SOC in the middle was at an average level. From the southern (Liaoning Province), central (Jilin Province) to the northern (Heilongjiang Province) of Northeast China, the SOC content of forest soil showed an obvious increasing trend. With the increase of latitude, the total organic carbon content of forest soil decreased significantly. It may be closely related to the thickness of soil genetic layer in northeast forest area (Xi et al., 2010). On the whole, the SOC content decreased gradually from northeast to southwest along the Northeast transect, this possibility was due to the influence of climate factors such as temperature and rainfall on soil intrinsic change and its formation (Zhou et al., 2016). 


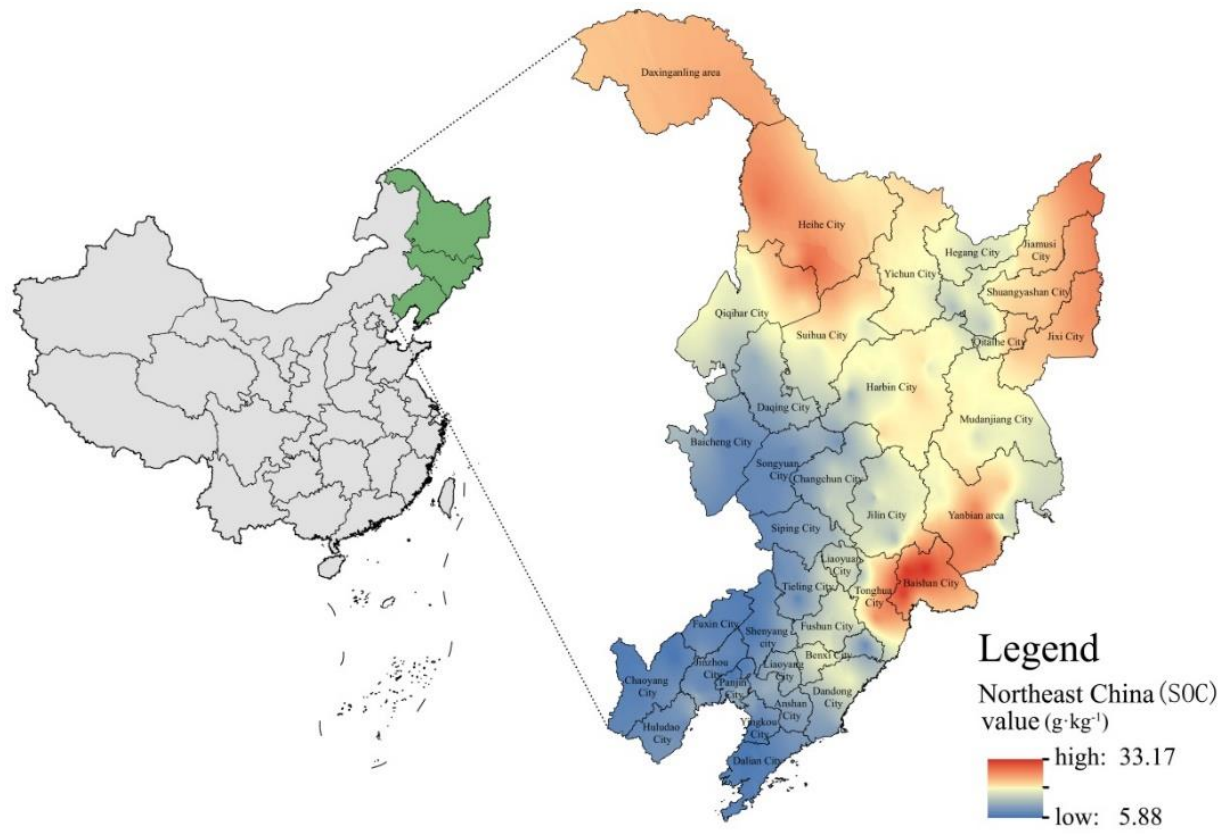

Figure 2. Distribution of SOC Northeast China

In terms of geographical location, Beijing and Tianjin are surrounded by Hebei Province. The SOC content in the north, northeast and southwest of the study area was higher than that in the middle and eastern regions, the overall spatial distribution of SOC decreased from the north to the south. According to Figure 3 , the content of SOC was between $5.13 \mathrm{~g} \cdot \mathrm{kg}^{-1} \sim 14.85 \mathrm{~g} \cdot \mathrm{kg}^{-1}$, the average SOC content in Hebei Province was $9.73 \mathrm{~g} \cdot \mathrm{kg}^{-1}$, that in Beijing city was $8.08 \mathrm{~g} \cdot \mathrm{kg}^{-1}$, and that in Tianjin city was $10.80 \mathrm{~g} \cdot \mathrm{kg}^{-1}$. The northern part of Hebei Province was mostly located in Yanshan Mountains, and Bashang grassland in the northeast of Zhangjiakou had higher SOC content. The southwest of Hebei Province was located in the eastern piedmont plain of Taihang Mountains, and the content of SOC was also high (Cao et al., 2016). In the middle and eastern part of Hebei Province, the salt content of soil and groundwater was mainly from seawater, and the content of soil salt was higher than that of SOC (Tian et al., 2019).

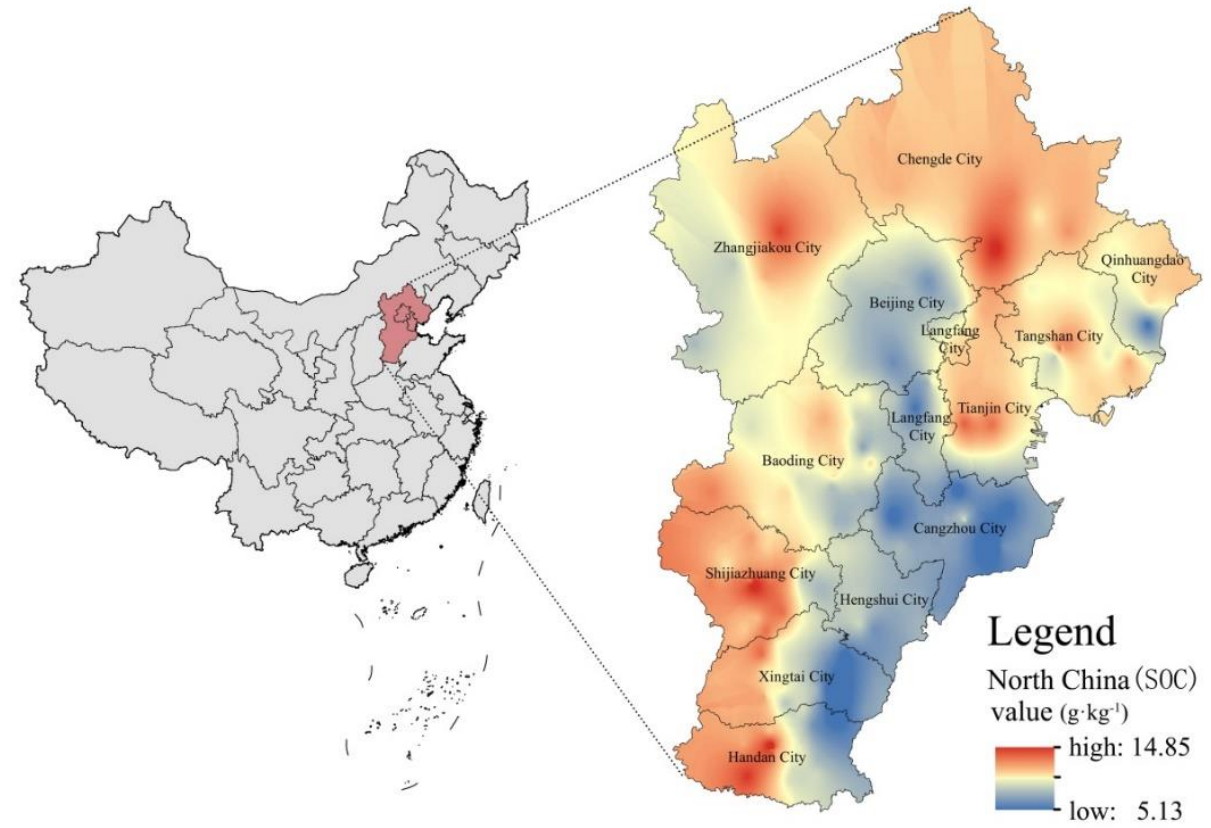


The East China of the study area mainly includes Shandong Province, Jiangsu Province, Shanghai city, Zhejiang Province and Fujian Province. It could be seen from Figure 4 that the SOC content in the study area increased gradually from north to south, the average SOC content in Shandong Province was 8.09 $\mathrm{g} \cdot \mathrm{kg}^{-1}$, and that in Jiangsu Province was $12.52 \mathrm{~g} \cdot \mathrm{kg}^{-1}$, the average SOC content in most areas of Shandong Province and Jiangsu Province was lower than $10.0 \mathrm{~g} \cdot \mathrm{kg}^{-1}$, and that in Shanghai city was $15.57 \mathrm{~g} \cdot \mathrm{kg}^{-1}$, and that in Zhejiang Province was $16.21 \mathrm{~g} \cdot \mathrm{kg}^{-1}$, and that in Fujian Province was $15.32 \mathrm{~g} \cdot \mathrm{kg}^{-1}$. The western and northern areas of Shandong Province were the vast plain areas, and the SOC content was generally low, and that in the south central region and the eastern mountainous and hilly areas was higher, and that in the west of Nansi Lake was also higher, and that in Dongying-Binzhou Yellow River Delta and Eastern Shandong coastal zone was the lowest (Dai et al., 2017). The SOC content in Zhejiang Province was decreasing from southwest to northeast, which was related to the distribution of topography and soil types in Zhejiang Province, and the topography inclines from southwest to northeast. The SOC content of Fujian Province was lower in the eastern coastal areas and higher in the western inland areas, the higher the altitude was that, the lower the temperature was in the western region, while the lower altitude area in the East had higher temperature, more convenient agricultural production and lower SOC content, the main reason was that the content of SOC in the western region was higher because of the higher altitude and lower temperature in the western region, while in the lower altitude area in the East, the temperature was higher, the agricultural production was more convenient and the SOC content was lower (Qi et al., 2017).

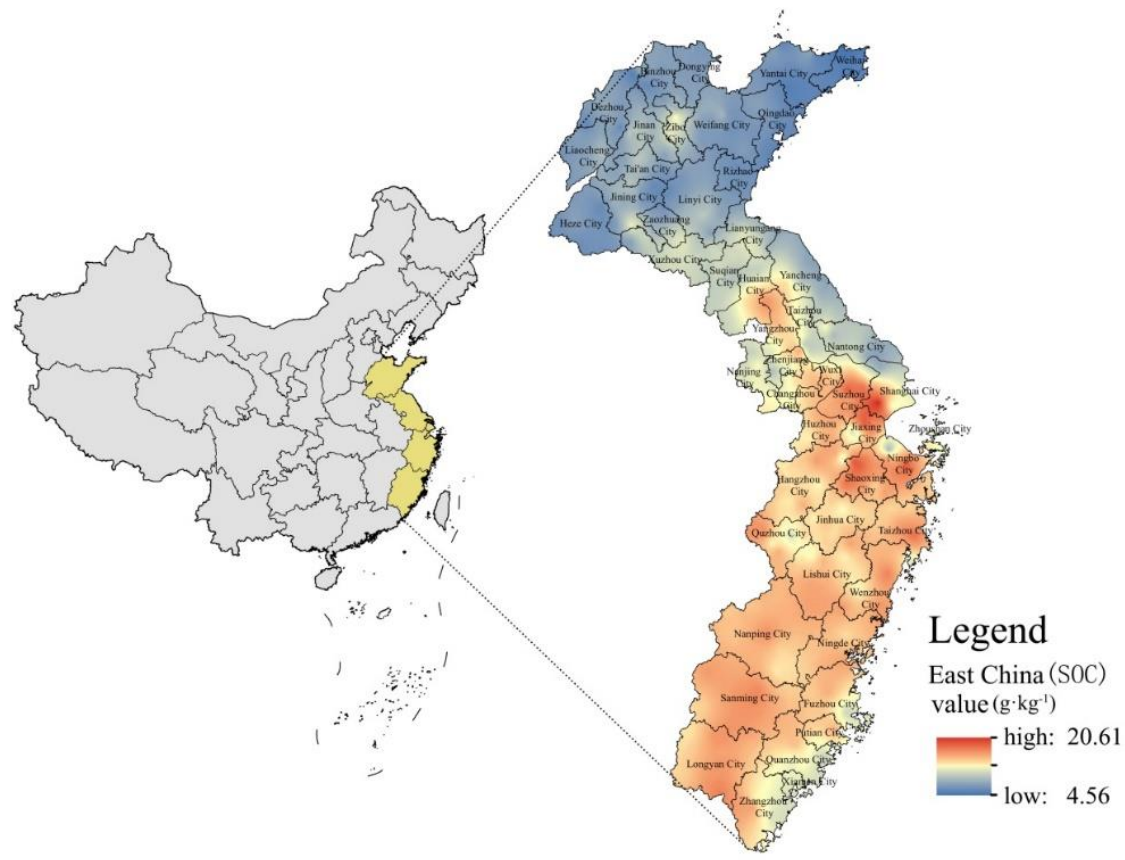

Figure 4. Distribution of SOC in East China

The South China of the study area included Guangdong Province. It could be seen from Figure 5 that the content of SOC was between $10.94 \mathrm{~g} \cdot \mathrm{kg}^{-1}$ to $17.44 \mathrm{~g} \cdot \mathrm{kg}^{-1}$, with an average of $15.32 \mathrm{~g} \cdot \mathrm{kg}^{-1}$, the content of SOC in the southeast coastal area and Leizhou peninsula was lower than that in the northern area, while that in red soil, lateritic red soil and paddy soil was higher. Guangdong was located in the tropical and subtropical areas, where the hydrothermal conditions were well, the vegetation grew luxuriantly, and the microbial activities were intense, so the decomposition rate of SOC was also fast (Luo et al., 2018). 


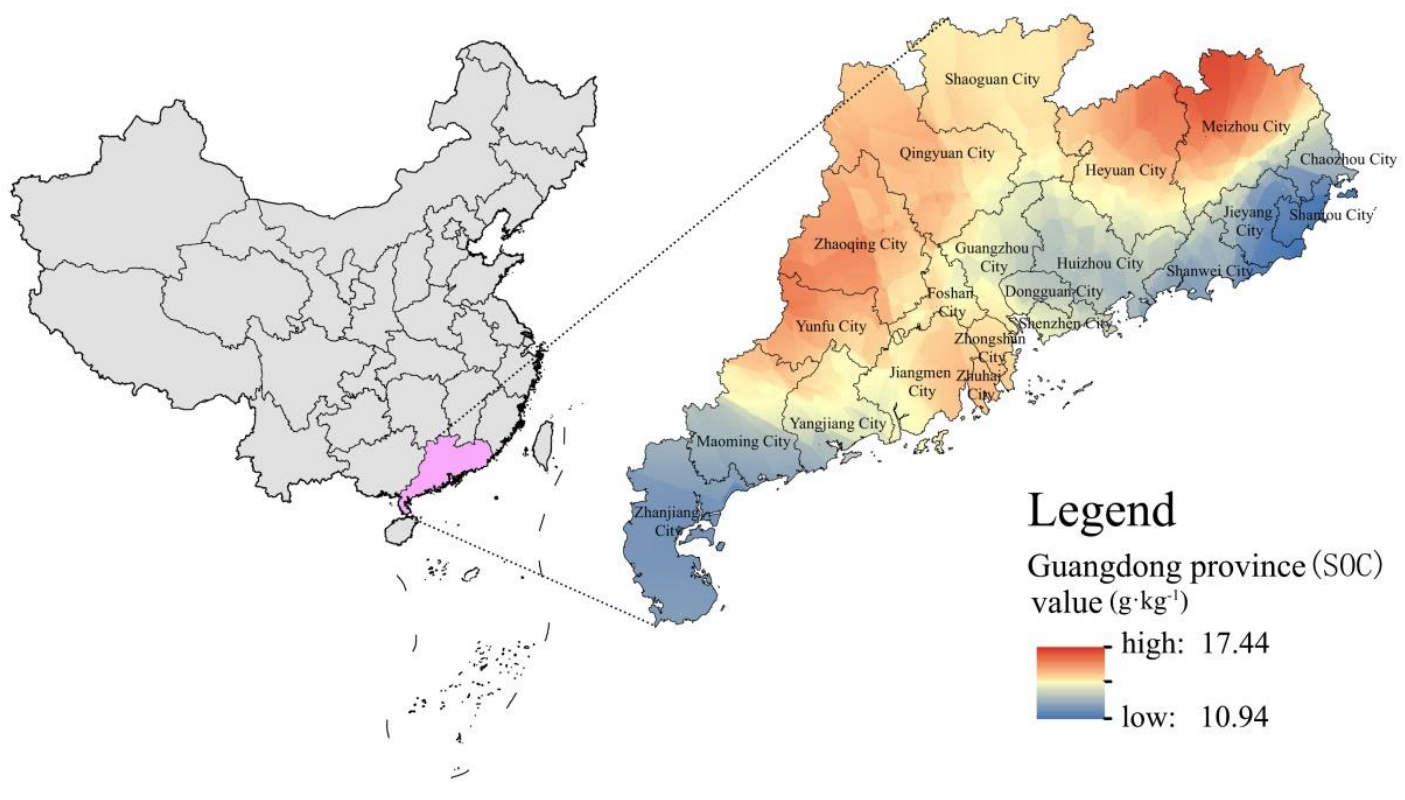

Figure 5. Distribution of SOC in Guangdong Province

The South China of the study area included Hainan Province also. It could be seen from Figure 6 that the content of SOC was between $3.69 \mathrm{~g} \cdot \mathrm{kg}^{-1}$ to $14.97 \mathrm{~g} \cdot \mathrm{kg}^{-1}$, with an average of $8.99 \mathrm{~g} \cdot \mathrm{kg}^{-1}$. Hainan Province was surrounded by low and flat, high in the middle, with Wuzhi Mountain and Hegeling as the core of uplift, descending step by step from the outer periphery, consisting of mountains, hills, plateaus and plains, with clear cascade structure. The high value area of surface SOC in Hainan Province was mainly distributed in the northern volcanic rock area and the central mountain area (Qiongzhong, Wuzhishan, Baisha, Tunchang), and decreased from the high value area to the coastal area. The SOC content in the eastern region was higher than that in the western region (Fang, 2012).

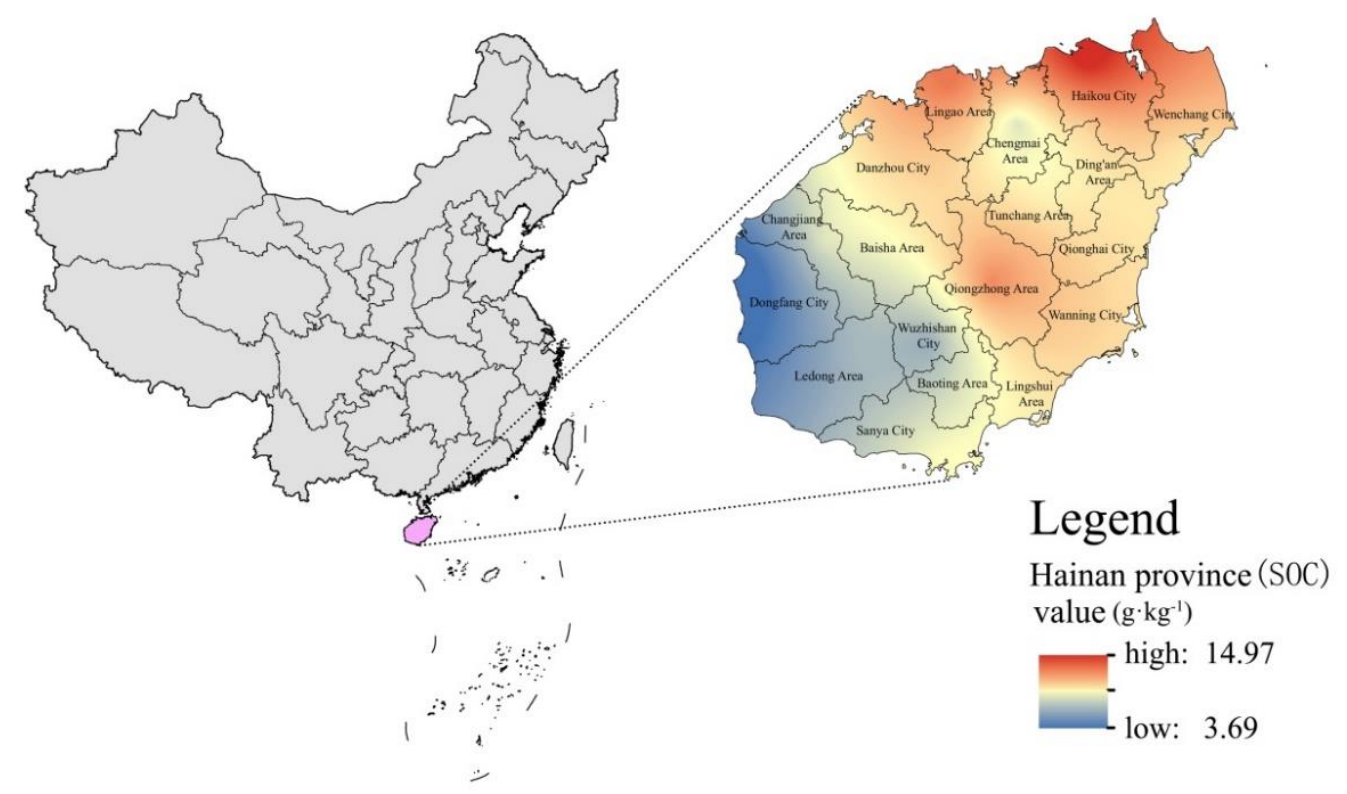




\section{Effects of hydrothermal conditions on SOC distribution pattern}

\section{Effect of temperature on SOC distribution pattern}

Generally speaking, at higher temperature, the physical and chemical reaction process in the soil was faster, the microbial activity was strong and the metabolism was vigorous, the soil animals were active, and the crop growth rate was also fast. Therefore, the decomposition rate of SOC and nutrient were also fast, and the content of SOC and nutrient was relatively low. On the contrary, SOC was easy to accumulate (Gao et al., 2020; Tan et al., 2020; Bhattacharyya et al., 2020).

It could be seen from Figure 7 that the relationship between SOC content and annual average temperature was a cubic curve, $y=-0.01076 x^{3}+0.5032 x^{2}-6.9794 x+39.1888,(\mathrm{r}=0.7374, \mathrm{n}=780, \quad P<$ 0.01 ), it reached the bottom of the curve at about $10^{\circ} \mathrm{C}$ and the high point at about $21^{\circ} \mathrm{C}$. By calculating the derivative of the curve, the two inflection points of the curve were $10.42^{\circ} \mathrm{C}$ and $20.75^{\circ} \mathrm{C}$ respectively. As shown in Figure 7, according to the inflection point of the curve, the relationship between organic carbon content and hydrothermal conditions was studied in the temperature range of $<10.42^{\circ} \mathrm{C}, 10.42^{\circ} \mathrm{C} \sim 20.75^{\circ} \mathrm{C}$ and $>20.75^{\circ} \mathrm{C}$.

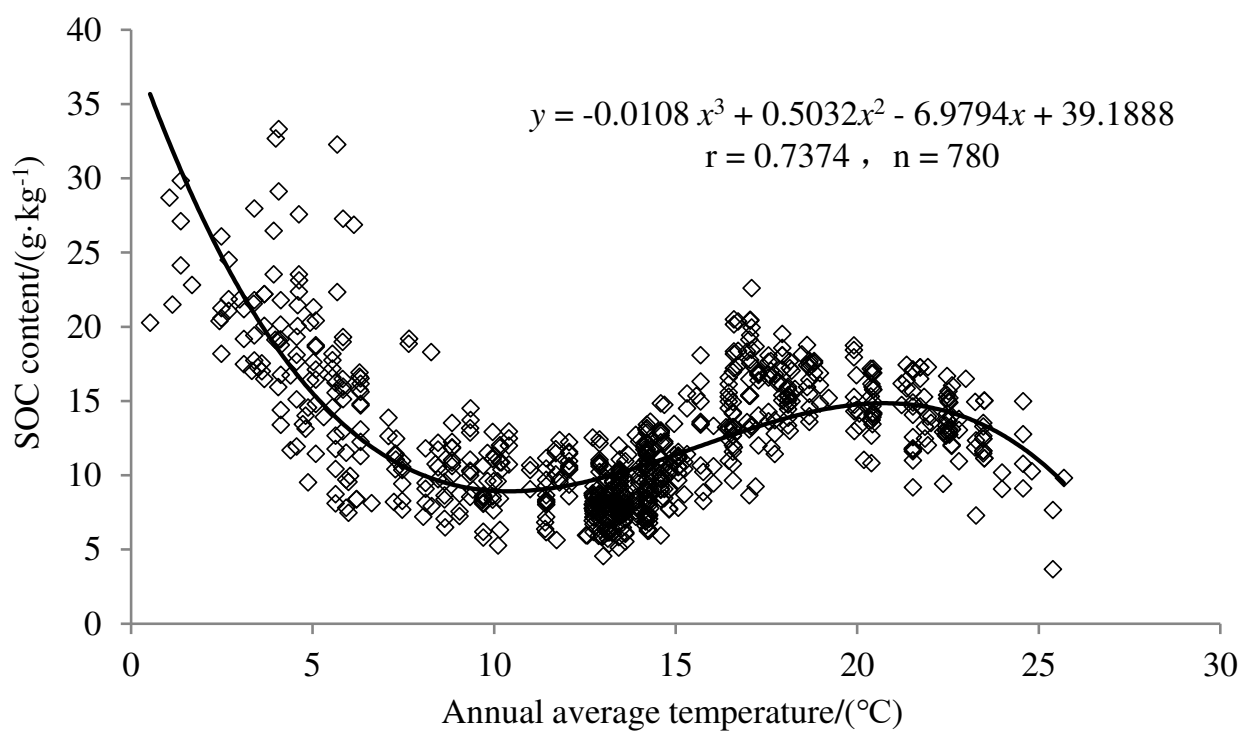

282

283

284

285

286

287

288

289

290

291

292

293

294

295

296

297

298

299

300

301

Figure 7. Relationship between SOC and annual average temperature $(n=883)$

As shown in Table 3 , in the region of $<10.42^{\circ} \mathrm{C}$, it mainly included Heilongjiang Province, Jilin Province and northern part of Hebei Province, the SOC content had a very significant relationship with annual average temperature, $\mathrm{P} / \mathrm{T}$ and annual accumulated temperature of $\geq 10^{\circ} \mathrm{C}, \mathrm{r}=7357^{* *}, \mathrm{r}=0.7934^{* * *}, \mathrm{r}=-$ $0.7467^{* *}$, respectively; The correlation between SOC content and annual average precipitation was weak $(\mathrm{r}=0.1543)$; The results showed that: in the area of annual average temperature $<10.42^{\circ} \mathrm{C}$, the annual average precipitation index was not related to the accumulation of SOC content, and the temperature index was the main contributing factor to the accumulation of SOC content. The annual accumulated temperature of $\geq 10^{\circ} \mathrm{C}$ had a negative correlation with the accumulation of organic carbon, which was slightly higher than the annual average temperature, and played a major negative correlation, while the P/T had a major positive correlation with the accumulation of organic carbon

In the region of $10.42^{\circ} \mathrm{C} \sim 20.75^{\circ} \mathrm{C}$, it mainly included Liaoning Province, Hebei Province, Shandong Province, Beijing City, Tianjin city, Jiangsu Province, Zhejiang Province, Shanghai city and Fujian Province, the SOC content had a very significant relationship with annual precipitation, annual average temperature, water temperature ratio and annual accumulated temperature $\geq 10^{\circ} \mathrm{C}, \mathrm{r}=0.8039^{* *} 、 0.8341^{* *}$, $0.7724^{* *}, 0.8293^{* * *}$, respectively; The results showed that: in the area of annual average temperature of $10.42^{\circ} \mathrm{C} \sim 20.75^{\circ} \mathrm{C}$, precipitation index and temperature index jointly determined the distribution of organic carbon content, and both played a negative correlation role. The correlation between annual accumulated 
temperature and SOC content was the best, while the correlation between P/T and SOC content was poor.

The correlation between annual mean temperature and SOC content was slightly lower than that between annual precipitation and SOC content, and the contribution of precipitation index to SOC accumulation was higher.

The region of above $20.75{ }^{\circ} \mathrm{C}$ mainly included Fujian Province, Guangdong Province and Hainan Province, the SOC content was negatively correlated with the annual mean temperature and the annual accumulated temperature of $\geq 10^{\circ} \mathrm{C}, \mathrm{r}=-0.5690^{* *}, \mathrm{r}=-0.6701^{* * *}$, respectively, while the SOC content was significantly correlated with the annual average precipitation $\left(\mathrm{r}=0.4517^{*}\right)$ and the water temperature ratio $\left(\mathrm{r}=0.4471^{*}\right)$; The results showed that: in the region with annual average temperature $>20.75{ }^{\circ} \mathrm{C}$, temperature index was the main negative correlation contribution factor of SOC content accumulation, while precipitation index had no strong effect on SOC content accumulation. Among them, the negative correlation effect of annual accumulated temperature $\geq 10^{\circ} \mathrm{C}$ on the accumulation of organic carbon content was slightly higher than the annual average temperature, which played a major negative correlation role.

Table 3. Changes of SOC under different annual average temperature in the eastern China Coastal Monsoon Region $\left(g^{\bullet} \mathrm{kg}^{-1}\right)$

\begin{tabular}{|c|c|c|c|}
\hline & $<10.42^{\circ} \mathrm{C}$ & $10.42^{\circ} \mathrm{C} \sim 20.75^{\circ} \mathrm{C}$ & $>20.75^{\circ} \mathrm{C}$ \\
\hline $\begin{array}{c}\text { Temperature } \\
\text { range }\end{array}$ & $\begin{array}{l}\text { Heilongjiang } \\
\text { Province, Jilin } \\
\text { Province, Liaoning } \\
\text { Province, Hebei } \\
\text { Province }\end{array}$ & $\begin{array}{l}\text { Liaoning Province, Hebei } \\
\text { Province, Shandong Province, } \\
\text { Beijing city, Tianjin city, } \\
\text { Jiangsu Province, Zhejing } \\
\text { Province, Shanghai city, Fujian } \\
\text { Province, Guangdong Province }\end{array}$ & $\begin{array}{l}\text { Fujian Province, } \\
\text { Guangdong } \\
\text { Province, Hainnan } \\
\text { Province }\end{array}$ \\
\hline Number of samples & 206 & 489 & 85 \\
\hline $\begin{array}{l}\text { Relationship with } \\
\text { annual average } \\
\text { precipitation }\end{array}$ & $\begin{array}{l}y=2 \mathrm{E}-08 x^{3}-5 \mathrm{E}- \\
05 x^{2}+0.0367 x+ \\
5.2147 \\
\mathrm{r}=0.1543\end{array}$ & $\begin{array}{l}y=-2 \mathrm{E}-08 x^{3}+6 \mathrm{E}-05 x^{2}- \\
0.0562 x+23.622 \\
r=-0.8039^{* *}\end{array}$ & $\begin{array}{l}y=1 \mathrm{E}-08 x^{3}-7 \mathrm{E}- \\
05 x^{2}+0.1272 x- \\
65.432 \\
\mathrm{r}=0.4517^{*}\end{array}$ \\
\hline $\begin{array}{l}\text { Relationship with } \\
\text { annual average } \\
\text { temperature }\end{array}$ & $\begin{array}{l}y=-1.7476 x+ \\
26.013 \\
r=-0.7357^{* *}\end{array}$ & $\begin{array}{l}y=-0.0788 x^{3}+3.7071 x^{2}- \\
55.95 x+282.2 \\
r=-0.8341^{* *}\end{array}$ & $\begin{array}{l}y=-1.3729 x+ \\
44.318 \\
r=-0.5690^{*}\end{array}$ \\
\hline $\begin{array}{c}\text { Relationship with } \\
\mathrm{p} / \mathrm{t}\end{array}$ & $\begin{array}{l}y=1 \mathrm{E}-07 x^{3}- \\
0.0003 x^{2}+0.1662 x \\
+1.3595 \\
\mathrm{r}=0.7934^{* *}\end{array}$ & $\begin{array}{l}y=-0.0001 x^{3}+0.0282 x^{2}- \\
1.7084 x+40.58 \\
r=-0.7724^{* *}\end{array}$ & $\begin{array}{l}y=9 \mathrm{E}-05 x^{3}- \\
0.0237 x^{2}+2.0334 x \\
-43.494 \\
r=0.44^{71^{*}}\end{array}$ \\
\hline $\begin{array}{l}\text { Relationship with } \\
\text { the annual } \\
\text { accumulated } \\
\text { temperature } \geq 10^{\circ} \mathrm{C}\end{array}$ & $\begin{array}{l}y=-0.0097 x+ \\
47.525 \\
r=-0.7467^{* *}\end{array}$ & $\begin{array}{l}y=-1 \mathrm{E}-09 x^{3}+2 \mathrm{E}-05 x^{2}- \\
0.1175 x+203.48 \\
r=-0.8293^{* *}\end{array}$ & $\begin{array}{l}y=-0.0044 x+ \\
49.828 \\
r=-0.6701^{* *}\end{array}$ \\
\hline Average value & 14.9084 & 11.2847 & 13.2247 \\
\hline Minimum value & 5.2722 & 4.5588 & 3.6714 \\
\hline Maximum value & 33.3094 & 22.6084 & 17.4406 \\
\hline Standard deviation & 5.9619 & 3.7442 & 2.5074 \\
\hline
\end{tabular}

Note: $* P<0.05, * * P<0.01, n=780$. The same below.

\section{Effect of annual average precipitation on SOC distribution pattern}

Precipitation is closely related to soil moisture and directly affects soil moisture, soil aeration and soil redox process to a great extent. Soil water directly affected the activity of soil microorganisms, and participated in the process of mineral weathering, organic matter synthesis and decomposition, so the impact of precipitation on SOC content was direct (Cui et al., 2019; Liu et al., 2016a). However, precipitation was not the only factor in the accumulation of SOC. Temperature could also directly or indirectly affected the process of microbial activity through precipitation, thus affected the accumulation of SOC. Therefore, according to the division standard of annual average precipitation (drought $<400 \mathrm{~mm}$, 
semi-arid $0 \sim 400 \mathrm{~mm}$, semi-humid area 400 800 $\mathrm{mm}$ and humid area $>800 \mathrm{~mm}$ ), this paper continued to discuss the main influencing factors of SOC under different regional precipitation, as shown in Table 4.

In the region of $0 \mathrm{~mm} \sim 400 \mathrm{~mm}$ precipitation, SOC content had a very relationship correlation with annual average precipitation, annual average temperature, $\mathrm{P} / \mathrm{T}$ and annual accumulated temperature of $\geq 10^{\circ} \mathrm{C}, \mathrm{r}=0.6922^{* *}, \mathrm{r}=-0.8908^{* *}, \mathrm{r}=0.9031^{* *}, \mathrm{r}=0.8808^{* *}$, respectively. The correlation between SOC content and $\mathrm{P} / \mathrm{T}$ was the best, which indicated that the coupling effect of annual average precipitation and annual average temperature played an important role in SOC accumulation.

In the region of $400 \mathrm{~mm} \sim 800 \mathrm{~mm}$ precipitation, SOC content had a very significantly relationship with annual mean temperature, $\mathrm{P} / \mathrm{T}$ and annual accumulated temperature $\geq 10^{\circ} \mathrm{C}, \mathrm{r}=0.8576^{* *}, \mathrm{r}=-0.8233^{* *}, \mathrm{r}=$ $0.8731^{* *}$, respectively. The correlation between SOC content and annual average precipitation was $\mathrm{r}=$ 0.1000 , which indicated that SOC content was not correlated with annual average precipitation, and SOC content was negatively correlated with $\mathrm{P} / \mathrm{T}$. Therefore, in the area of $400 \sim 800 \mathrm{~mm}$ precipitation, temperature index played a major contribution factor to SOC accumulation.

The climate in eastern China was characterized by temperate monsoon climate and subtropical monsoon climate. The summer monsoon was the main source of precipitation in China. The vast areas in Southeast China were greatly affected by the southeast monsoon and southwest monsoon, and have more precipitation (Wang et al., 2013). Therefore, although the temperature of 12 counties (cities and districts) in Jilin Province near the sea of Japan, including Helong City, Fusong County, Linjiang City, Jiangyuan County, Tonghua County, Ji'an City, Huanren Manchu Autonomous County, Kuandian Manchu Autonomous County, Donggang City, Fengcheng City, Zhenxing District and Zhen'an District, was low, the precipitation could still reach more than $800 \mathrm{~mm}$. In order to eliminate the influence of the above 12 counties (cities, districts) on the overall statistical results, we removed the data of the above 12 counties (cities, districts) in the area with precipitation $>800 \mathrm{~mm}$, we found that the correlation between SOC content and annual average precipitation, annual average temperature, $\mathrm{P} / \mathrm{T}$ and annual accumulated temperature $\geq 10^{\circ} \mathrm{C}$ was better than that before removing the data, at this time, the SOC content had a very significant relationship with the annual average temperature and annual accumulated temperature $\geq 10^{\circ} \mathrm{C}, \mathrm{r}=-0.6933^{* *} \mathrm{r}=-0.7058^{* *}$, respectively, and also had a significant relationship with the annual average precipitation and $\mathrm{P} / \mathrm{T}, \mathrm{r}=-$ $0.5782^{* *}, \mathrm{r}=-0.5172^{* *}$, respectively. This showed that the temperature factor was still the main factor of SOC accumulation in the area with precipitation $>800 \mathrm{~mm}$, followed by precipitation factor. Among them, the accumulation effect of annual accumulated temperature $\geq 10^{\circ} \mathrm{C}$ on organic carbon content was slightly higher than the annual average temperature.

358

359

360

361

362

Table 4. Changes of SOC under different annual average precipitation in the eastern China Coastal Monsoon Region $\left(\mathrm{g} \cdot \mathrm{kg}^{-1}\right)$

\begin{tabular}{|c|c|c|c|}
\hline & $0 \sim 400(\mathrm{~mm})$ & $400 \sim 800(\mathrm{~mm})$ & $>800(\mathrm{~mm})$ \\
\hline $\begin{array}{l}\text { Temperature } \\
\text { precipitation }\end{array}$ & $\begin{array}{l}\text { Heilongjiang } \\
\text { Province, Jilin } \\
\text { Province, Hebei } \\
\text { Province }\end{array}$ & $\begin{array}{l}\text { Heilongjiang Province, } \\
\text { Liaoning Province, Jilin } \\
\text { Province, Hebei Province, } \\
\text { Shandong Province, } \\
\text { Beijing city, Tianjin city }\end{array}$ & $\begin{array}{l}\text { Liaoning Province, Jilin } \\
\text { Province, Zhejiang } \\
\text { Province, Fujian Province, } \\
\text { Shanghai city, Jiangsu } \\
\text { Province, Shandong } \\
\text { Province, Guangdong } \\
\text { Province, Hainan Province }\end{array}$ \\
\hline $\begin{array}{l}\text { Number of } \\
\text { samples }\end{array}$ & 28 & 430 & $\begin{array}{l}322(311) \\
y=-8 \mathrm{~F}-06 x^{2}+00253 x-\end{array}$ \\
\hline $\begin{array}{l}\text { Relationship } \\
\text { with annual } \\
\text { average } \\
\text { precipitation }\end{array}$ & $\begin{array}{l}y=9 \mathrm{E}-05 x^{3}- \\
0.0951 x^{2}+33.089 x \\
-3794 \\
\mathrm{r}=0.6922^{* *}\end{array}$ & $\begin{array}{l}y=2 \mathrm{E}-07 x^{3}-0.0004 x^{2}+ \\
0.2598 x-38.663 \\
r=0.1000\end{array}$ & $\begin{array}{l}y=-8 \mathrm{E}-06 x^{2}+0.0253 x- \\
4.2907 \\
\quad\left(y=-1 \mathrm{E}-05 x^{2}+0.0331 x-\right. \\
10.588) \\
\mathrm{r}=-0.3841^{*} \quad\left(\mathrm{r}=-0.5782^{* *}\right. \\
)\end{array}$ \\
\hline $\begin{array}{l}\text { Relationship } \\
\text { with annual }\end{array}$ & $\begin{array}{l}y=0.7515 x^{2}- \\
11.46 x+51.479 \\
r=0.8908^{* *}\end{array}$ & $\begin{array}{l}y=0.0098 x^{3}-0.1097 x^{2}- \\
1.6591 x+26.948 \\
\mathrm{r}=0.8576^{* *}\end{array}$ & $\begin{array}{l}y=-0.0219 x^{3}+1.0418 x^{2}- \\
15.358 x+81.85\end{array}$ \\
\hline
\end{tabular}




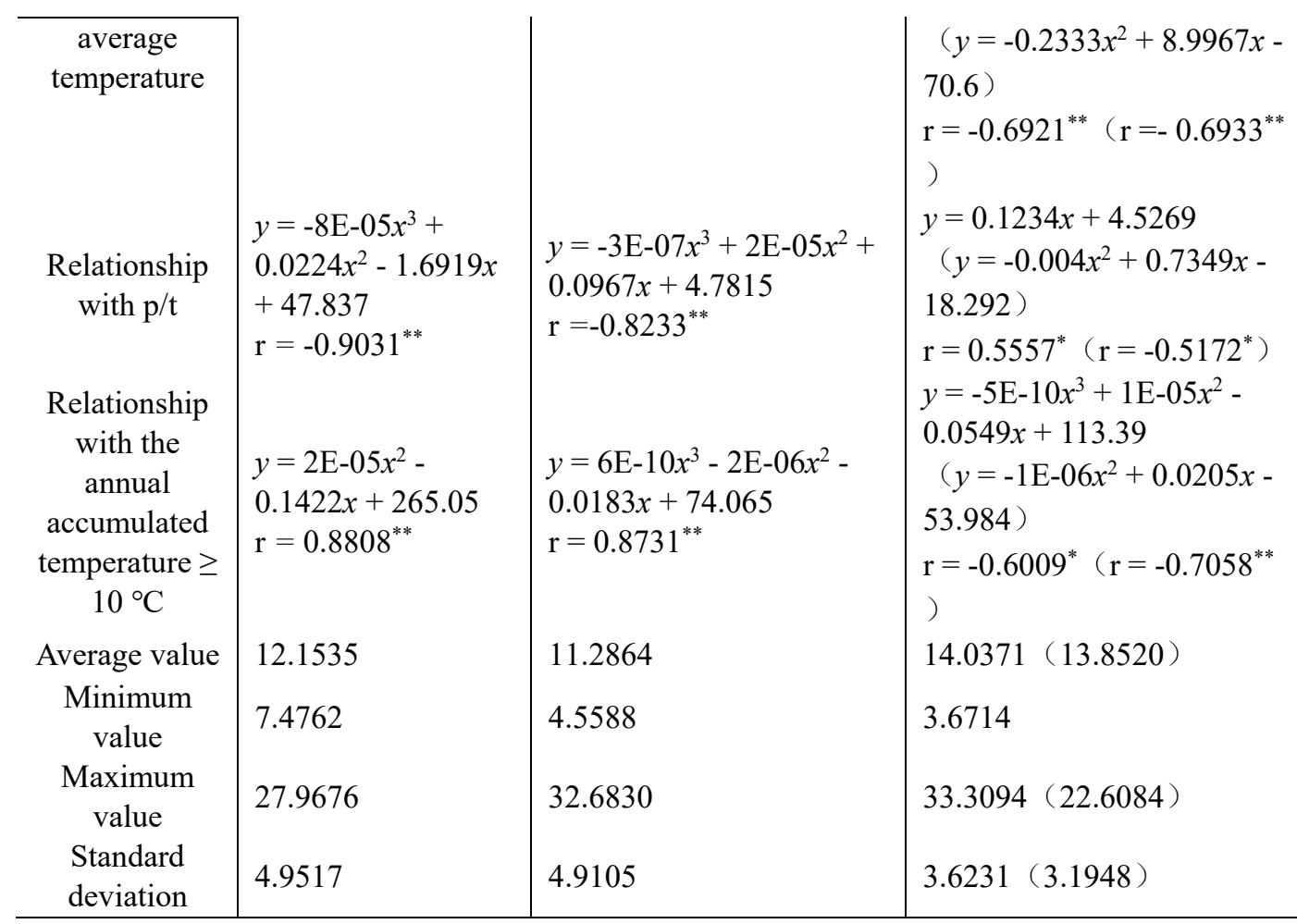

Note: The data in ( ) in Table 4, these were the statistical data after deleting the data of 12 counties in Jilin Province, including Helong, Fusong, Linjiang, Jiangyuan, Tonghua, Ji'an, Huanren, Kuandian, Donggang, Fengcheng, Zhenxing and Zhen'an districts in Liaoning Province.

\section{Effects of hydrothermal conditions on SOC distribution pattern}

Based on the principal component analysis results of SPSS 15.0, the author selected annual accumulated temperature $\geq 10^{\circ} \mathrm{C}$ and annual average precipitation as two independent variables of organic carbon model. After multiple combinations of variables, the correlation of different combinations was repeatedly screened, and the following models were obtained.

Design: $C=\alpha+\beta \bullet \log (T)+\gamma \bullet \frac{C}{\log (P)}+\varepsilon \bullet \frac{C \bullet \log (P)}{\log (T)}$

Then: $C=\frac{\alpha+\beta \bullet \log (T)}{\frac{\log (P) \bullet \log (T)-\gamma \bullet \log (T)-\varepsilon \bullet \log (P) \bullet \log (P)}{\log (P) \bullet \log (T)}}$

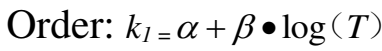

$$
k_{2}=\frac{\log (P) \bullet \log (T)-\gamma \bullet \log (T)-\varepsilon \bullet \log (P) \bullet \log (P)}{\log (P) \bullet \log (T)}
$$

$$
k_{3}=\frac{\gamma \bullet \log (T)+\varepsilon \bullet \log (P) \bullet \log (P)}{\log (P) \bullet \log (T)}=\frac{\gamma}{\log (P)}+\frac{\varepsilon \bullet \log (P)}{\log (T)}
$$

Then: $C=\frac{k_{1}}{k_{2}}=+\beta \bullet \log (T)+k_{3} \bullet C$

Order: $k=C$

Then: $k=C=\frac{\alpha \bullet \log (P) \bullet \log (T)+\beta \bullet \log (P) \bullet \log (T)^{2}}{\log (P) \bullet \log (T)-\gamma \bullet \log (T)-\varepsilon \bullet \log (P)^{2}}$

Among them, $C$ was the organic carbon content $\left(\mathrm{g} \cdot \mathrm{kg}^{-1}\right), \alpha, \beta, \gamma$ and $\varepsilon$ were constants, $T$ was the annual accumulated temperature of $\geq 10^{\circ} \mathrm{C}\left({ }^{\circ} \mathrm{C}\right), P$ was the annual average precipitation $(\mathrm{mm})$.

"Humification coefficient" refers to the ratio of added organic carbon to a more stable soil carbon pool (Poeplau et al., 2015). That was to say, the ratio of the amount of plant residues (measured by carbon) added 
to the soil one year after decomposition to the original amount was generally used to measure the degree of humus formation by biochemical and chemical action of animal, plant and microbial residues under the action of microorganisms. In this paper, we redefined a new constant $\mathrm{K}$, the humification constant of regional organic carbon for many years, which was a constant under the comprehensive influence of hydrothermal conditions.

SPSS 15.0 multiple regression was used to obtain the following analysis results, as shown in Table 5. $\alpha$ $=-6.4467, \beta=1.8001, \gamma=1.3525, \varepsilon=0.6550$ were calculated. The $p$-values of $\alpha, \beta, \gamma$ and $\varepsilon$ were all 0 or Closed to 0 , with extremely significant correlation.

Table 5. Analysis of model results

\begin{tabular}{c|c|c|c|c|c|c|c|c}
\hline & Coefficients & $\begin{array}{c}\text { Standard } \\
\text { error }\end{array}$ & $\mathbf{t}$ Stat & P-value & $\begin{array}{c}\text { Lower } \\
\mathbf{9 5 \%}\end{array}$ & Upper95\% & $\begin{array}{c}\text { lower } \\
\text { limit } \\
\mathbf{9 5 . 0 \%}\end{array}$ & $\begin{array}{c}\text { upper } \\
\text { limit } \\
\mathbf{9 5 . 0 \%}\end{array}$ \\
\hline$\alpha$ & -6.1488 & 0.1234 & -49.8408 & $4.4468 \mathrm{E}-244$ & -6.3910 & -5.9066 & -6.3910 & -5.9066 \\
$\beta$ & 1.7187 & 0.0324 & 53.0170 & $3.5453 \mathrm{E}-260$ & 1.6551 & 1.7824 & 1.6551 & 1.7824 \\
$\gamma$ & 1.3420 & 0.0081 & 166.2373 & 0 & 1.3261 & 1.3578 & 1.3261 & 1.3578 \\
$\varepsilon$ & 0.6596 & 0.0031 & 209.9597 & 0 & 0.6534 & 0.6658 & 0.6534 & 0.6658 \\
\hline
\end{tabular}

Table 6. Model multiple regression statistics

\begin{tabular}{c|c}
\hline Related indicators & Numerical value \\
\hline Multiple R & 0.9999 \\
R Square & 0.9998 \\
Adjusted R Square & 0.9998 \\
Standard error & 0.0723 \\
Observations & 780 \\
\hline
\end{tabular}

Table 7. Analysis of model variance

\begin{tabular}{l|c|c|c|c|c}
\hline & df & SS & MS & F & Significance F \\
\hline & 3 & 16611.9430 & 5537.3143 & 1058121.1996 & 0 \\
Residual & 776 & 4.0609 & 0.0052 & & \\
Total & 779 & 16616.0039 & & & \\
\hline
\end{tabular}

According to the regression statistics in Table 6 and Table 7, $\mathrm{R}^{2}=0.9998(\mathrm{r}=0.9999)$, and the standard error was $0.0672, \mathrm{P}<0.01$, with extremely significant correlation.

According to table 5 , the equation of SOC prediction model was as follows:

\section{Discussion}

\section{Effect of temperature on SOC accumulation}

In this paper, from the farthest Daxinganling area of Heilongjiang Province to Sanya City of Hainan Province, the straight-line distance is more than 5000 kilometers, the annual average temperature varies from $-3.9^{\circ} \mathrm{C} \sim 25.7^{\circ} \mathrm{C}$, and the accumulated temperature of $\geq 10^{\circ} \mathrm{C}$ varies from $1770^{\circ} \mathrm{C} \sim 9443^{\circ} \mathrm{C}$. Studies had shown that the effective accumulated temperature of $\geq 10^{\circ} \mathrm{C}$ generally increased after 1985 , and the

413 typical effective accumulated temperature zone of $\geq 10^{\circ} \mathrm{C}$ moved northward as a whole. The isolines of $4143400^{\circ} \mathrm{C}$ and $8000^{\circ} \mathrm{C}$ of the effective accumulated temperature of $\geq 10^{\circ} \mathrm{C}$ have a significant trend of migration 
to the northeast. The area of $0 \sim 3400^{\circ} \mathrm{C}$ of the effective accumulated temperature of $\geq 10^{\circ} \mathrm{C}$ decreases significantly, while the area of $3400^{\circ} \mathrm{C} \sim 8000^{\circ} \mathrm{C}$ of the effective accumulated temperature of $\geq 10^{\circ} \mathrm{C}$ increases significantly (Liu et al., 2013), this might also be the climatic reason for the decrease of SOC content in Northeast China (Liu et al., 2016b). The effective accumulated temperature $\geq 10^{\circ} \mathrm{C}$ was an indicator to reflect the heat demand of biological growth and development or to measure regional heat resources. It basically reflected the linear relationship between crop growth rate and temperature. The correlation between effective accumulated temperature $\geq 10^{\circ} \mathrm{C}$ and annual average temperature was $\mathrm{r}=$ $0.9881^{* * *}$ (see Figure 8).

SOC decomposition might be sensitive to temperature rise, and SOC decayed faster in warmer environment (Zhang et al., 2015). The effect of temperature on SOC was very complex. Temperature directly affected the accumulation of SOC through the activity of microorganisms. Under the same fertility level, the higher the annual average temperature was, the higher the crop biomass was, and the more litter and crop stubble were returned to the soil. Therefore, the input of SOC will increase. But at the same time, the higher the annual average temperature, the faster the decomposition rate of organic matter (Cao et al., 2007). Only from the cumulative correlation between temperature and SOC, the contribution of annual accumulated temperature $\geq 10^{\circ} \mathrm{C}$ to $\mathrm{SOC}$ accumulation was slightly higher than that of annual average temperature in the regions of annual average temperature $<10.42^{\circ} \mathrm{C}, 10.42^{\circ} \mathrm{C} \sim 20.75^{\circ} \mathrm{C}$ and $>20.75^{\circ} \mathrm{C}$, and in the regions of annual average precipitation $0 \mathrm{~mm} \sim 400 \mathrm{~mm}, 400 \mathrm{~mm} \sim 800 \mathrm{~mm}$ and $>800 \mathrm{~mm}$.

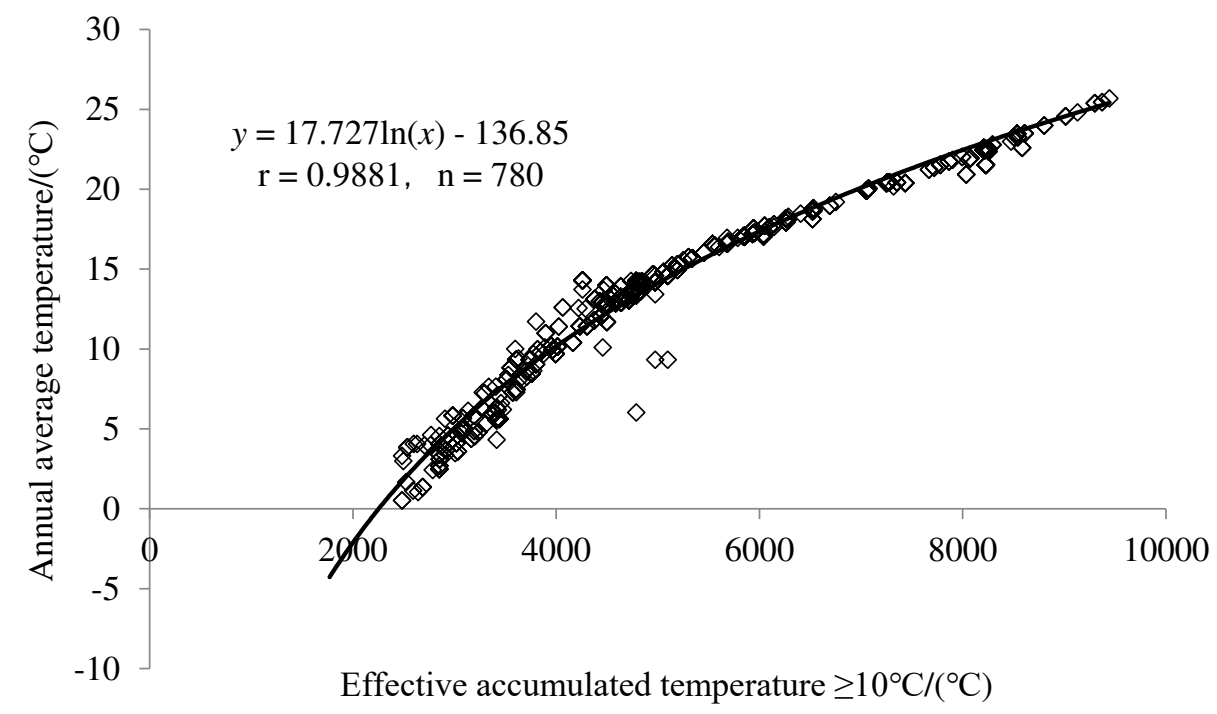

Figure 8. Relationship between annual average temperature and effective accumulated temperature $\geqslant$

$$
10^{\circ} \mathrm{C}(\mathrm{n}=883)
$$

\section{Effect of precipitation on SOC accumulation}

From the aspect of annual average precipitation, from $346 \mathrm{~mm}$ in Baicheng city of Jilin Province to $2300 \mathrm{~mm}$ in Wuzhishan City of Hainan Province, the correlation between annual average precipitation and SOC accumulation was poor, $r=0.3501$ (see Figure 9). Changes in precipitation patterns will have a significant impact on the function and structure of terrestrial ecosystems, as water was the basic driving force for almost all chemical and biological processes, included plant growth and survival, photosynthesis, microbial activity and soil respiration (Gerten et al., 2008). The combined effects of temperature rise and precipitation decrease (or increase) on carbon sequestration rate were less than the sum of their respective effects, with the individual and simultaneous global changes, the change of SOC presented a nonlinear model (Zhang et al., 2019), SOC decomposition was more sensitive to temperature change than precipitation (Guntiñas et al., 2013). 


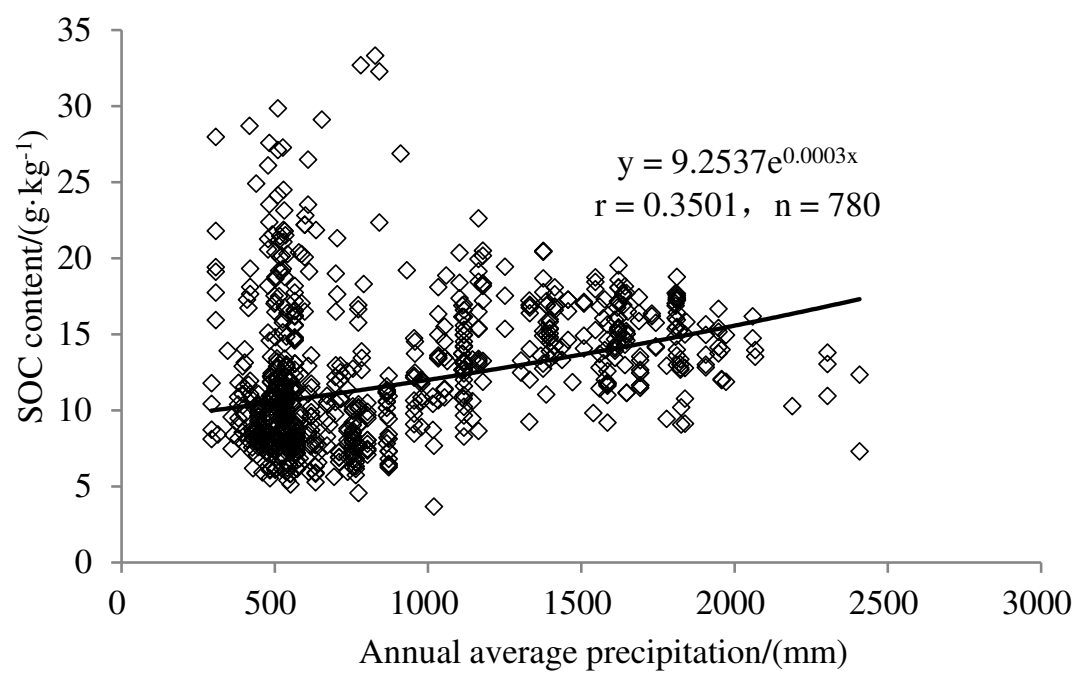

Figure 9. Relationship between SOC content and annual average precipitation $(\mathrm{n}=780)$

In order to reduce the impact of precipitation on SOC, soil samples were collected in a wide geographical area along the $400 \mathrm{~mm}$ isohyet in China. The results show that temperature accounted for more than half of the variation of SOC, which was far greater than the comprehensive influence of water availability, soil properties, vegetation types and soil types (Tan et al., 2020). Therefore, most of the contribution of water availability to SOC variability should include the contribution of temperature. The effects of temperature and precipitation on the distribution pattern of SOC in agroecosystem had been widely studied, but the comprehensive effects of these parameters on the macro scale were still less reported.

As shown in Figure 10, after removing the above 12 counties (districts, cities), the accumulation of SOC content by annual average temperature and annual average precipitation was interactive. In the area of annual average precipitation $>800 \mathrm{~mm}$, the relationship between SOC content and annual average temperature was nonlinear in 311 sample points after removing the above 12 counties (districts, cities). In the region of $>800 \mathrm{~mm}$, the annual average temperature $<20.75{ }^{\circ} \mathrm{C}$, the temperature had a positive correlation with the accumulation of organic carbon, and the SOC content increased with the increase of the annual average temperature. In the region of $>800 \mathrm{~mm}$, the annual average temperature $>20.95^{\circ} \mathrm{C}$, the temperature had a negative correlation with the accumulation of organic carbon, and the SOC content decreased with the increase of the annual average temperature. Therefore, the effected of warming and precipitation on soil temperature and humidity werre not independent, but show interaction (Guanlin et al., 2017). In warmer and wetter climates, microbial activity was higher, which resulted in less isolated SOC (Yang et al., 2011). however, with the increased of soil temperature, the activity of microorganisms and the content of derived compounds increased, which leaded to the degradation of the unstable component SOC, this process need to be promoted with the increase of precipitation (Chen et al., 2020). 


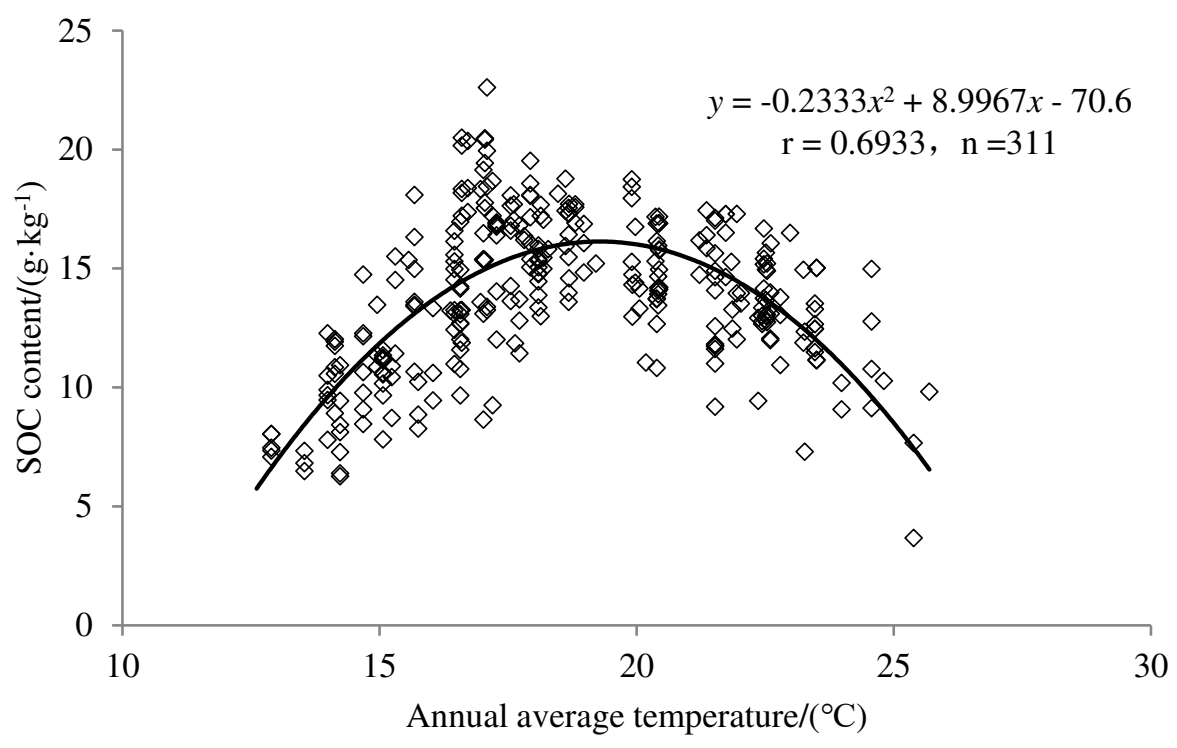

Figure 10. Relationship between SOC content and annual average temperature in the region with annual precipitation $>800 \mathrm{~mm}(\mathrm{n}=311)$

SOC content was significantly correlated with water temperature ratio $\left(\mathrm{r}=0.7503^{* *}\right)$ (as shown in Figure 11). SOC content showed an increasing trend with the increase of $P / T$. Studies havd shown that the change of water heat gradient had an effect on the content of soil light fraction organic carbon, and there was a very significant positive correlation between SOC content and water temperature ratio (Gerten et al., 2008; Li et al., 2009). Precipitation and temperature havd a positive interaction on the accumulation of SOC. SOC was the result of precipitation, temperature and other factors (Wang et al., 2002).

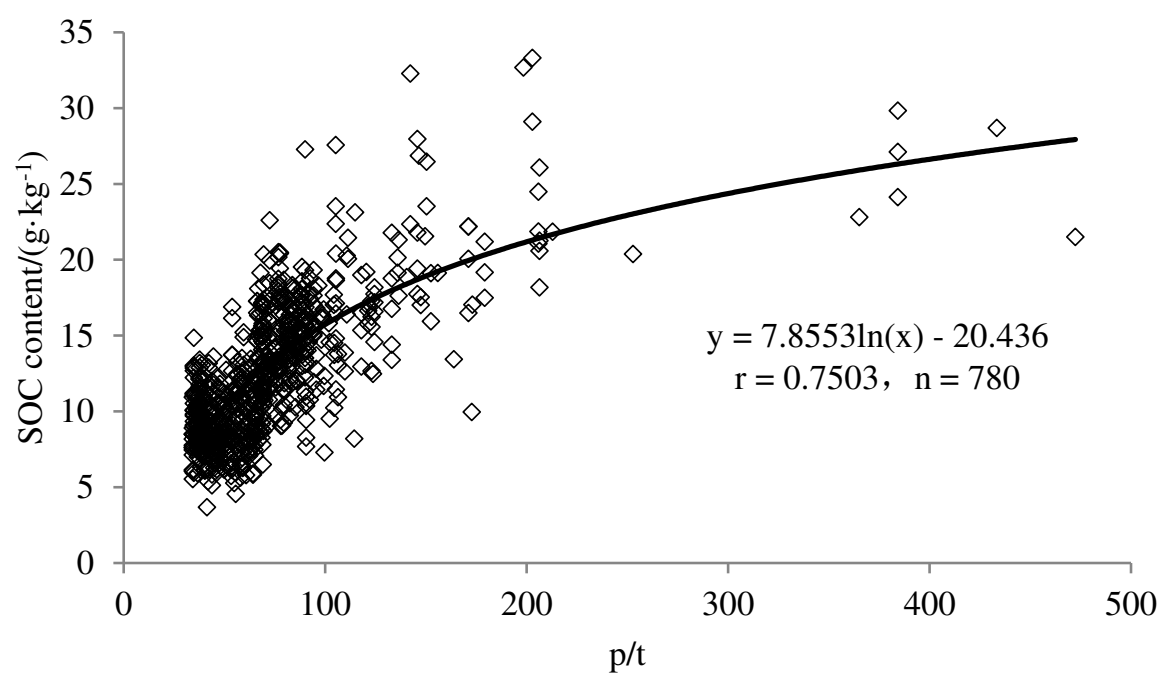

Figure 11. Relationship between SOC content and $\mathrm{p} / \mathrm{t}(\mathrm{n}=780)$

\section{Effect of hydrothermal conditions on SOC accumulation}

At the micro level, the spatial variability of SOC was the result of the combined action of natural factors and human factors. The most significant factors affecting SOC were soil type, land use, soil texture, topography, soil physical and chemical properties and many other factors (Gelaw et al., 2014; Arrouays et al., 2001; Schillaci et al., 2017; Tziachris et al., 2019; Zhang et al., 2018). At the same time, soil type, soil 
texture and topography were almost unchanged, while land use had a great impact on SOC. The chemical composition and physical structure of each part of the plant were different, especially the root was more difficult to treat, so the average residence time in the soil was longer (Heitkamp et al., 2012; Rasse, et al., 2005).

Figure 12 reflected the simulation relationship between the predicted value and the real value of SOC. The results showed that the cubic curve equation could better simulated the relationship between the predicted value and the real value of SOC. As mentioned above, with the temperature and precipitation changing individually or simultaneously, the change of SOC presented a nonlinear model (Zhang et al., 2019). The correlation coefficient $r=0.7048^{* *}$, and the cubic curve equation could better simulated the relationship between the predicted value and the real value of SOC.

503

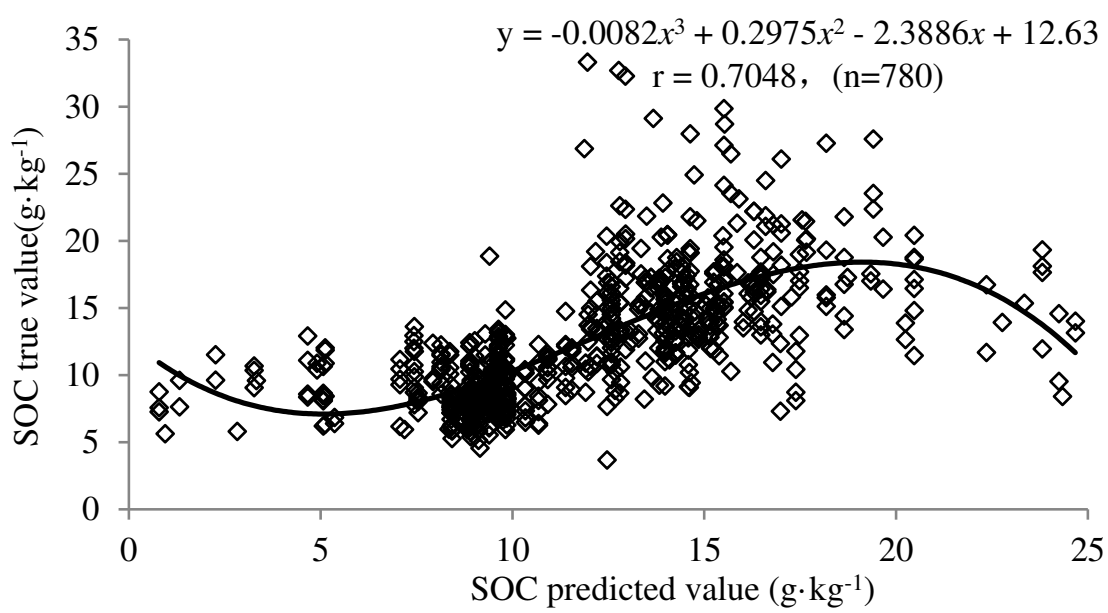

Figure 12. Comparison of SOC predicted value and real value $(n=780)$

\section{Conclusion}

In the eastern coastal monsoon region of China, temperature has a negative correlation with the accumulation of organic carbon when the annual average temperature is less than $10.18{ }^{\circ} \mathrm{C}$, and the water temperature ratio has a positive correlation with the accumulation of SOC, and the content of SOC increases with the increase of the water temperature ratio; in the region of $10.18{ }^{\circ} \mathrm{C} \sim 20.95{ }^{\circ} \mathrm{C}$, the annual average temperature and the annual average precipitation have a significant positive correlation, and the water temperature ratio has a positive correlation with the accumulation of SOC In the region of $>20.95{ }^{\circ} \mathrm{C}$, the temperature has a negative correlation with the accumulation of organic carbon, and the water temperature ratio has no correlation with the accumulation of SOC.

In the range of $0 \mathrm{~mm}$ to $400 \mathrm{~mm}$, temperature has a positive correlation with the accumulation of organic carbon, while the water temperature ratio has a negative correlation with the accumulation of SOC In the 
region of $>800 \mathrm{~mm}$, the annual average temperature $<20.95{ }^{\circ} \mathrm{C}$, the temperature has a positive correlation with the accumulation of organic carbon, and in the region of $>20.95^{\circ} \mathrm{C}$, the temperature has a negative correlation with the accumulation of organic carbon, but the water temperature ratio has no significant effect on the accumulation of organic carbon.

In this paper, a comprehensive model of the effects of annual mean temperature and annual mean precipitation on organic carbon accumulation is established, which can better reflect the comprehensive effects of annual mean temperature and annual mean precipitation on organic carbon accumulation. The cubic curve equation can better fit the relationship between the predicted value and the actual value of SOC.

\section{Declarations}

540 Ethics approval and consent to participate: Not applicable

541 Consent for publication: All participants consent for publication.

542 Availability of data and materials: Not applicable.

543 Competing interests: The authors declare no conflict of interest.

544 Funding: This study was funded by Guangxi Major Scientific and Technological Projects 545 (NO.AA17204077), Guangxi Science and Technology Base and Talent Special Project (NO. AD18126012), 546 Guangxi First Class Discipline (Geography) Construction Funds, Guangxi Bagui Scholars Special Fund, 547 Innovation and Entrepreneurship Training Program for College Students of Nanning Normal University, the Opening Foundation of Key Laboratory of Beibu Gulf Environment Change and Resources Use, Ministry of Education (GTEU-KLOP-X1704).

Authors' contributions: Conceptualization, Shutian Liu and Xiansheng Xie; methodology, Shutian Liu and Yanlin Hou; software, Xiansheng Xie; formal analysis, Xiaochuan Wang and Xianda Hou; data curation, Xinxin Feng and Keyu Lin; writing - original draft preparation, Shutian Liu and Shuojin Wang; writing — review and editing, Sen Dou and Mei Huang; and supervision, Yanlin Hou and Shugang Jia. All authors have read and agreed to the published version of the manuscript.

Acknowledgements: Not applicable.

\section{REFERENCES}

Abramoff, R. Z., Torn, M. S., Georgiou, K. (2019): Soil Organic Matter Temperature Sensitivity Cannot be Directly Inferred From Spatial Gradients. Global Biogeochemical Cycles 33(6): 761-776.

Arrouays, D., Deslais, W., Badeau, V. (2001) The carbon content of topsoil and its geographical distribution in France[J]. Soil Use Manage 17:7-11.

B.C. Liang, A.J. Vanden Bygaart, J.D. MacDonald, et al (2020) Angers. Revisiting no-till's impact on soil organic carbon storage in Canada[J]. Soil \& Tillage Research 4:198.

Bhattacharyya R, Ghosh A, Zhang Y Q, et al (2020) Land use affects temperature sensitivity of soil organic carbon decomposition in macroaggregates but not in bulk soils in subtropical Oxisols of Queensland, Australia[J]. Soil and Tillage Research 198:10456.

Cao H J, Wang J K, Li S Y, et al (2007) Effect of Gradients of Precipitation and Temperature and Fertilization on Organic Carbon and Nitrogen of Soils in Northeastern China[J]. Journal of Soil and Water Conservation 4:122-125+149.

Cao Xianghui, Long Huaiyu, Zhou Jiaogen, et al (2016) Analysis of spatial variability and influencing factors of top soil organic carbon and total nitrogen in Hebei Province[J]. Journal of Plant Nutrition and Fertilizer 22(4):937-948.

Chen Q, Niu B, Hu Y, et al (2020) Warming and increased precipitation indirectly affect the composition and turnover of labile-fraction soil organic matter by directly affecting vegetation and microorganisms[J]. Science of the Total Environment 714:136787.

Chen, L. F., He, Z. B., Du, J. (2016): Patterns and environmental controls of soil organic carbon and total nitrogen in alpine ecosystems of Northwest China. - Catena 137: 37-43.

Christopher Poeplau, Thomas Kätterer, Martin A. Bolinder, et al (2015) Low stabilization of aboveground crop residue carbon in sandy soils of Swedish long-term experiments[J]. Geoderma 3:237-238. 
Cui Y X, Fang L C, Deng L, et al (2019) Patterns of soil microbial nutrient limitations and their roles in the variation of soil organic carbon across a precipitation gradient in an arid and semi-arid region[J]. Science of The Total Environment 658:1440-1451.

Dai Jierui, Pang Xugui, Dong Jian (2017) Soil Organic Carbon Pool and Temporal Variation Characteristics in Shandong Province[J]. Geoscience 31(2):386-393.

Dash P K, Bhattacharyya P, Roy K S, et al (2019) Environmental constraints' sensitivity of soil organic carbon decomposition to temperature, management practices and climate change[J]. Ecological Indicators 107:105644.

Deng Jiao Jiao, Zhu Wen Xu, Zhou Yong Bin, et al (2018) Effects of different land use patterns on the soil microbial community diversity in montane region of eastern Liaoning Province, China[J]. The journal of applied ecology 29(7):2269-2276.

Diel J, Franko U (2020) Sensitivity analysis of agricultural inputs for large-scale soil organic matter modelling[J]. Geoderma 363:114172

Dieter G, Luo Y Q, Guerric L M, et al (2008) Sower by Modelled effects of precipitation on ecosystem carbon and water dynamics in different climatic zones[J]. Global Change Biology 14:2365-2379.

D.P. Rasse, C. Rumpel, M.F. Dignac (2005) Is soil carbon mostly root carbon? Mechanisms for a specific stabilization[J]. Plant Soil 269:341-356.

Felton Andrew J, Slette Ingrid J, Smith Melinda D, et al (2020) Precipitation amount and event size interact to reduce ecosystem functioning during dry years in a mesic grassland[J]. Global change biology 26(2):658-668.

F. Heitkamp, A. Jacobs, H.F. Jungkunst, et al (2012) Processes of soil carbon dynamics and ecosystem carbon cycling in a changing world[J]. Springer Dordrecht 4:395-428.

Gan Haihua, Wu Shunhui, Fan Xiudan (2003) Reserves and spatial distribution characteristics of soil organic carbon in Guangdong Province[J]. Chinese Journal of Applied Ecology 9:1499-1502.

Gao X S, Huang R, Li J, et al (2020) Temperature induces soil organic carbon mineralization in urban park green spaces, Chengdu, Southwestern China: Effects of planting years and vegetation types[J]. Urban Forestry \& Urban Greening 54:126761.

Gelaw, A.M., Singh, B.R., Lal, R.(2014) Soil organic carbon and total nitrogen stocks under different land uses in a semi-arid watershed in Tigray, Northern Ethiopia[J]. Agric. Ecosyst. Environ 188:256-263.

Ghimire R, Bista P, Machado S, et al (2019) Long-term Management Effects and Temperature Sensitivity of Soil Organic Carbon in Grassland and Agricultural Soils[J]. Scientific Reports 9(1):1-10.

Gong Y H, Zhao D M, Ke W B, et al (2020) Legacy effects of precipitation amount and frequency on the aboveground plant biomass of a semi-arid grassland[J]. Science of The Total Environment 705:135899.

Guanlin L I, Kim S, Park M, et al (2017) Short-Term Effects of Experimental Warming and Precipitation Manipulation on Soil Microbial Biomass C and N, Community Substrate Utilization Patterns and Community Composition[J]. Pedosphere 27(4):714-724.

Guntiñas M E, Gil-Sotres F, Leirós, M C, et al (2013) Trasar-Cepeda Sensitivity of soil respiration to moisture and temperature[J]. Journal of Soil Science and Plant Nutrition 13(2):445-461.

Hui D F, Yu C L, Deng Q, et al (2018) Effects of precipitation changes on switchgrass photosynthesis, growth, and biomass: A mesocosm experiment[J].Plos one. https://doi.org/10.1371/journal.pone.0192555

Jing Zhang, Kelin Hu, Kejiang Li, et al (2017) Simulating the effects of long-term discontinuous and continuous fertilization with straw return on crop yields and soil organic carbon dynamics using the DNDC model[J]. Soil \& Tillage Research 165:302-314.

Jun Xia, Qing-Yun Duan, Yong Luo, et al (2017) Climate change and water resources: Case study of Eastern Monsoon Region of China[J]. Advances in Climate Change Research 8(2):63-67.

Li Z Q, Wang J K, Cao H J, et al (2009) Effect of Gradients of Precipitation and Temperature and Fertilization on Light Fraction Organic Carbon and Nitrogen of Soils in Northeastern China[J]. Chinese Journal of Soil Science 40(5):10141017.

Lin Yang, Min Song, A-Xing Zhu, et al (2019) Predicting soil organic carbon content in croplands using crop rotation and Fourier transform decomposed variables[J]. Geoderma 340:289-302.

Lin Yang, Xianglin He, Feixue Shen, et al (2020) Improving prediction of soil organic carbon content in croplands using phenological parameters extracted from NDVI time series data[J]. Soil \& Tillage Research 42:196.

Liu S H, Yan D H, Weng B S, et al (2013) Spatiotemporal Evolution of Effective Accumulated Temperature $\geqslant 10^{\circ} \mathrm{C}$ in China in Recent 50 Years[J]. Arid Zone Research 30(4):689-696.

Liu S T, Dou S, Hou Y L, et al (2016) Relationship between Area of Straw Returning to the Field and Content of Soil Organic Carbon in China[J]. Journal of Jilin Agricultural University 38(6):723-732+738.

Liu S T, Dou S, Zheng W, et al (2016) Temperatures based on soil testing and fertilizer recommendation data set[J]. Journal of Agro-Environment Science 35(7):1413-1420.

Long Guo, Haitao Zhang, Tiezhu Shi, et al (2019) Prediction of soil organic carbon stock by laboratory spectral data and airborne hyperspectral images[J]. Geoderma 337:32-41.

LV Li-ping (2013) Study on Variation of Soil Organic Carbon in Hainan[D]. Hainan University.

Ma W J, Li J, Gao Y, et al (2020) Responses of soil extracellular enzyme activities and microbial community properties to interaction between nitrogen addition and increased precipitation in a semi-arid grassland ecosystem[J]. Science of the Total Environment 703: 134691. 
M.I. Khalil, D.A. Fornara, B. Osborne (2019) Simulation and validation of long-term changes in soil organic carbon under permanent grassland using the DNDC model[J]. Geoderma 42:1-15.

641

Moritz Laub, Sergey Blagodatsky, Rong Lang, et al (2018) A mixed model for landscape soil organic carbon prediction across continuous profile depth in the mountainous subtropics[J]. Geoderma 330:177-192.

National Agricultural Technology Extension Service Center (2014) Soil Testing Formula Fertilization Data Set (2005-2014) [M]. Beijing: China Agricultural Press.

Nave L E, Domke G M, Hofmeister K L, et al (2018) Reforestation can sequester two petagrams of carbon in US topsoils in a century[J]. Proceedings of the National Academy of Sciences of the United States of America 115(11):2776-2781.

Nimai Senapati, Nilantha R. Hulugalle, et al (2014) Modelling soil organic carbon storage with RothC in irrigated Vertisols under cotton cropping systems in the sub-tropics[J]. Soil \& Tillage Research 143:38-49.

Padilha M C, Vicente L E, Dematte J A, et al (2020) Using Landsat and soil clay content to map soil organic carbon of oxisols and Ultisols near São Paulo, Brazil[J]. Geoderma Regional 21:1-9.

Qi Li, Dongdong Chen, Liang Zhao, et al (2016) More than a century of Grain for Green Program is expected to restore soil carbon stock on alpine grassland revealed by field $13 \mathrm{C}$ pulse labeling[J]. Science of the Total Environment 550:17-26.

Qi Y B, Wang Y Y, Chen Y, et al (2017) Soil organic matter prediction based on remote sensing data and random forest model in Shaanxi Province[J]. Journal of Natural Resources 32(6):1074-1086.

Qian Li, Fengying Wei, Dongliang Li (2011) Interdecadal variation of East Asian summer monsoon and drought/flood distribution over eastern China in the last 159 years[J]. Journal of Geographical Sciences 21(4):579-593.

Ranjan Bhattacharyya, Avijit Ghosh, Yaqi Zhang, et al (2020) Land use affects temperature sensitivity of soil organic carbon decomposition in macroaggregates but not in bulk soils in subtropical Oxisols of Queensland, Australia[J]. Soil \& Tillage Research 62:198.

Rong Jiang, Wentian He, Wei Zhou, et al (2019) Exploring management strategies to improve maize yield and nitrogen use efficiency in northeast China using the DNDC and DSSAT models[J]. Computers and Electronics in Agriculture 166:112.

Sarah L. Gilhespy, Steven Anthony, Laura Cardenas, et al (2014) First 20 years of DNDC (DeNitrification DeComposition): Model Evolution[J]. Ecological Modelling 292:51-61.

Shumin Li, Jumei Li, Changsheng, et al (2016) Testing the RothC and DNDC models against long-term dynamics of soil organic carbon stock observed at cropping field soils in North China[J]. Soil \& Tillage Research 163:290-297.

Sakrabani Ruben, Hollis John (2018) Evaluating Changes in Soil Organic Matter with Climate Using CENTURY in England and Wales[J]. Journal of environmental quality 47(4):695-703.

Setyono H. Adi, Sabine Grunwald (2020) Integrative environmental modeling of soil carbon fractions based on a new latent variable model approach[J]. Science of the Total Environment 711:1-15.

Schillaci C., Acutis M., Lombardo L., et al (2017) Spatio-temporal top soil organic carbon mapping of a semi-arid Mediterranean region: The role of land use, soil texture, topographic indices and the influence of remote sensing data to modelling[J]. Sci. Total Environ. 601-602:821.

Song, X. D., Yang, J. Y., Zhao, M. S. (2019): Heuristic cellular automaton model for simulating soil organic carbon under land use and climate change: A case study in eastern China. - Agriculture, Ecosystems and Environment 269: 156-166.

Tian, F., Zhang, C. H., Zhang, J. L. (2019): Dynamic Changes of Soil Salt Distribution in Green Space of TEDA. - Journal of Irrigation and Drainage 38(S2): 78-82.

Tian Fei, ZHANG Chuhan, ZHANG Jinlong, et al (2019) The Dynamic Changes of Soil Salt Distribution in Green Space of TEDA[J]. Journal of Irrigation and Drainage 38(S2):8-82.

Tian Q Q, Han W X, Li X R, et al (2020) Clarifying the response of soil organic carbon storage to increasing temperature through minimizing the precipitation effect[J]. Geoderma 374:114398.

Tziachris P., Aschonitis V., Chatzistathis, T., et al (2019) Assessment of spatial hybrid methods for predicting soil organic matter using DEM derivatives and soil parameters[J]. Catena 174:206-216.

Vitharana U W, Mishra U, Mapa R B, et al (2019) National soil organic carbon estimates can improve global estimates[J]. Geoderma 337: 55-64

Wang C Y, He N P, Lv Y L (2016) Latitudinal patterns and factors affecting different soil organic carbon fractions in the eastern forests of China[J]. Acta Ecologica Sinica 36(11):3176-3188.

Wang D Q, Zhang Y C, Huang A (2013) Climatic features of the south-westerly low-level jet over southeast china and its association with precipitation over east China[J]. Asia-Pacific Journal of Atmospheric Sciences 49 (3):259-270.

Wang S P, Zhou G S, Lu Y C, et al (2002) Distribution of Soil Carbon, Nitrogen and Phosphorus Along Northeast China Transect (NECT) and Their Relationships with Climatic Factors[J]. Acta Phytoecologica Sinic 26 (5):513-517.

Wei Ya-wei, YU Da-pao, WANG Qing-jun, et al (2013) Soil organic carbon density and its influencing factors of major forest types in the forest region of Northeast China[J]. Chinese Journal of Applied Ecology 24(12):3333-3340.

Wei Ouyang, Yushu Shan, Fanghua Hao, et al (2014) Differences in soil organic carbon dynamics in paddy fields and drylands in northeast China using the CENTURY model[J]. Agriculture, Ecosystems and Environment 194:38-47.

W.L. Kutsch, M. Bahn, A. Heinemeyer (2009) Soil Carbon Dynamics: an Integrated Methodology[D]. Cambridge University Press, Cambridge.

Woolf Dominic, Lehmann Johannes (2019) Microbial models with minimal mineral protection can explain long-term soil organic carbon persistence.[J]. Scientific reports 9(1):6522. 
Wu Y, Wu J P, Saleem M, et al (2020) Ecological clusters based on responses of soil microbial phylotypes to precipitation explain ecosystem functions[J]. Soil Biology and Biochemistry 142:107717.

Xi Xiao-huan, Yang Zhong-fang, Cui Yu-jun, et al (2010) A study of soil carbon distribution and change in Northeast Plain[J]. Earth Science Frontiers 17(3):213-221.

Xiaobin Lin, Zhiping Wen, Wen Zhou, et al (2017) Effects of tropical cyclone activity on the boundary moisture budget over the eastern China monsoon region[J]. Advances in Atmospheric Sciences 34 (6):700-712.

Xiaohe Gu, Yancang Wang, Qian Sun, et al (2019) Hyperspectral inversion of soil organic matter content in cultivated land based on wavelet transform[J]. Computers and Electronics in Agriculture 167:1-7.

Xu H F, Demetriades A, Reimann C, et al (2019) Identification of the co-existence of low total organic carbon contents and low $\mathrm{pH}$ values in agricultural soil in north-central Europe using hot spot analysis based on GEMAS project data[J]. Science of The Total Environment 678:94-104.

Xueyu Chang, Binbin Wang, Yan Yan, et al (2018) Characterizing effects of monsoons and climate teleconnections on precipitation in China using wavelet coherence and global coherence[J]. Climate Dynamics 52(9):5213-5228.

Yan D, Li J Q, Pei J M, et al (2017) The temperature sensitivity of soil organic carbon decomposition is greater in subsoil than in topsoil during laboratory incubation[J]. Scientific reports 7(1):5181.

Yang Y H, Luo Y Q, Finzi A C, et al (2011) Carbon and nitrogen dynamics during forest stand development: a global synthesis[J]. New Phytologist 190(4):977-989.

Yin Zhou, Asim Biswas, Zhiqiang Ma, et al (2016) Revealing the scale-specific controls of soil organic matter at large scale in Northeast and North China Plain[J]. Geoderma 271:71-79.

Yiquan Ma, Majie Fan, Yongchao Lu, et al (2019) Stable isotope record of middle Eocene summer monsoon and its instability in eastern China[J]. Global and Planetary Change 175:103-112.

Zhang H., Wu P., Fan M., (2018) Dynamics and driving factors of the organic carbon fractions in agricultural land reclaimed from coastal wetlands in eastern China[J]. Ecol. Indic. 89:639-647.

Zhang K R, Dang H S, Zhang Q F, et al (2015) Soil carbon dynamics following land-use change varied with temperature and precipitation gradients: evidence from stable isotopes[J]. Global Change Biology 21(7):2762-2772.

Zhang L, Zheng Q F, Liu Y L, et al (2018) Combined effects of temperature and precipitation on soil organic carbon changes in the uplands of eastern China[J]. Geoderma 66:1105-1115.

Zhiyan Zuo, Renhe Zhang (2016) Influence of soil moisture in eastern China on the East Asian summer monsoon[J]. Advances in Atmospheric Sciences 133(2):151-163.

Biography

731

732

733

734

735

736

Dr. Shutian Liu obtained his B.S. Degree at college of resources and environment, Jilin

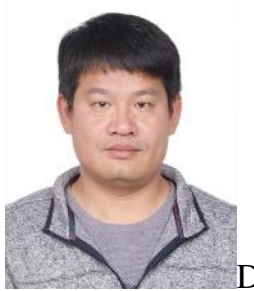
Agricultural University in China in 2005, and completed his M.S. and Ph.D at Jilin Agricultural University in China in July 2008 and 2016. Since 2017, he has been an associate professor researcher at Institute of geography and oceanography, Nanning Normal University, China. Until now, he has published 50+ papers. His current research is focused on agricultural geographic information specialty.

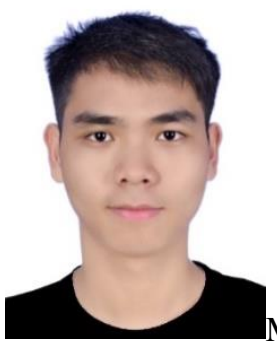

Mr. Xiansheng Xie obtained his bachelor's degree in Guangxi University of Finance and Economics in China in 2019. Since 2019, he is a graduate student of School of Geography and Planning, 
Dr. Xiaochuan Wang obtained his B.S. Degree at Changchun University of Science and

Technology in China in 2005, and completed his M.S. Degree at Jilin University in China in 2011. At present, he is engaged in management in the president's office of Nanning Normal University and has obtained the title of assistant researcher. He has been studying for a doctorate in business administration at Sehan University in South Korea since September 2019 and is expected to graduate in 2022. Until now, he has published nearly 10 academic papers. His current research is focused on the Science of Business

746 Administration.

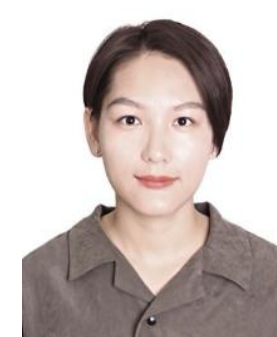

Miss Xinxin Feng, a 2018 undergraduate in Nanning Normal University, majored in physical geography

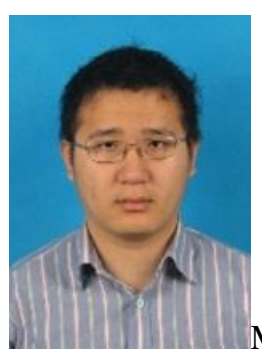

Mr. Xianda Hou received a bachelor's degree from Southwest Jiaotong University in 2010 and a master's degree from Beijing University of Aeronautics and Astronautics in December 2013. He has been an assistant researcher of Nanning Normal University since 2017. So far, he has published $10+$ papers. His current research focus is agricultural geographic information.

Mr. Shuojin Wang received his bachelor's degree from Jilin Agricultural University in

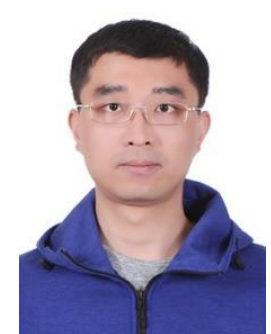
2006 and his master's degree from Beijing University of Aeronautics and Astronautics in July 2016. He has been an assistant researcher of Nanning Normal University since 2017. So far, he has published $10+$ papers. His current research focus is agricultural geographic information. 
Miss Keyu Lin received a bachelor's degree from Nanning Normal University in 2015 and studied for a master's degree at the school in September of the same year. Her research field is big data in agricultural geography.

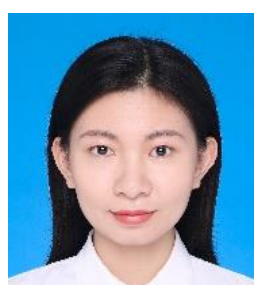

Miss Mei Huang received a bachelor's degree from Nanning Normal University in 2020, and studied for a master's degree at the school in September of the same year. Her current research focuses on agricultural geoinformatics.

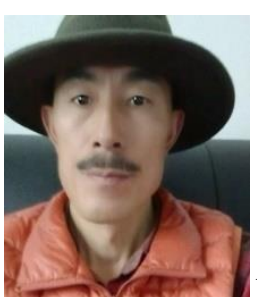
environment, Jilin Agricultural University of China in 1986 and his doctor's degree from Gifu University in July 2002. Since 2019, professor and researcher of Institute of geography and oceanography, Nanning Normal University, China. So far, he has published $50+$ papers. His current research direction is agricultural geographic information.

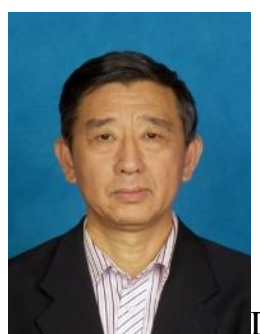

Dr. Yanlin Hou obtained his B.S. Degree at college of resources and environment, Jilin Agricultural University in China in 1983, and completed his M.S. and Ph.D at Jilin Agricultural University and Institute of Applied Ecology,Chinese Academy of Sciences, China in July 1986 and 1989. Since 2017, he has been an professor researcher at Institute of geography and oceanography, Nanning Normal University, China. Until now, he has published 150 + papers. His current research is focused on agricultural geographic information specialty. 
Dr. Sen Dou obtained his bachelor's degree from Jilin Agricultural University of China in 1981, and completed his master's degree and doctor's degree from Jilin Agricultural University of China in July 1984 and Shenyang Agricultural University in July 1989. Since 1994, he has been a professor, researcher and doctoral supervisor of resource and Environment College of Jilin Agricultural University. So far, he has published $150+$ papers. He has been engaged in the study of SOM and humic substances (HS) for nearly 40 years, with field applications for soil improvement and remediation. The theory of soil organic improving had been put forward as a research focus which claims that under certain conditions, organic materials can be directly returned to the field without undergoing an excessive decomposition to renew the aged humic substances in the soil with a more aliphatic, simple and "fresh" structure. Dr. Dou Sen developed a new mode of straw return and the engineering technology SEDB (Straw Enrichment and Deep Burial). He later invented the tube plough for straw return and the microbial remediation agent for oil-contaminated soil. 
Figures

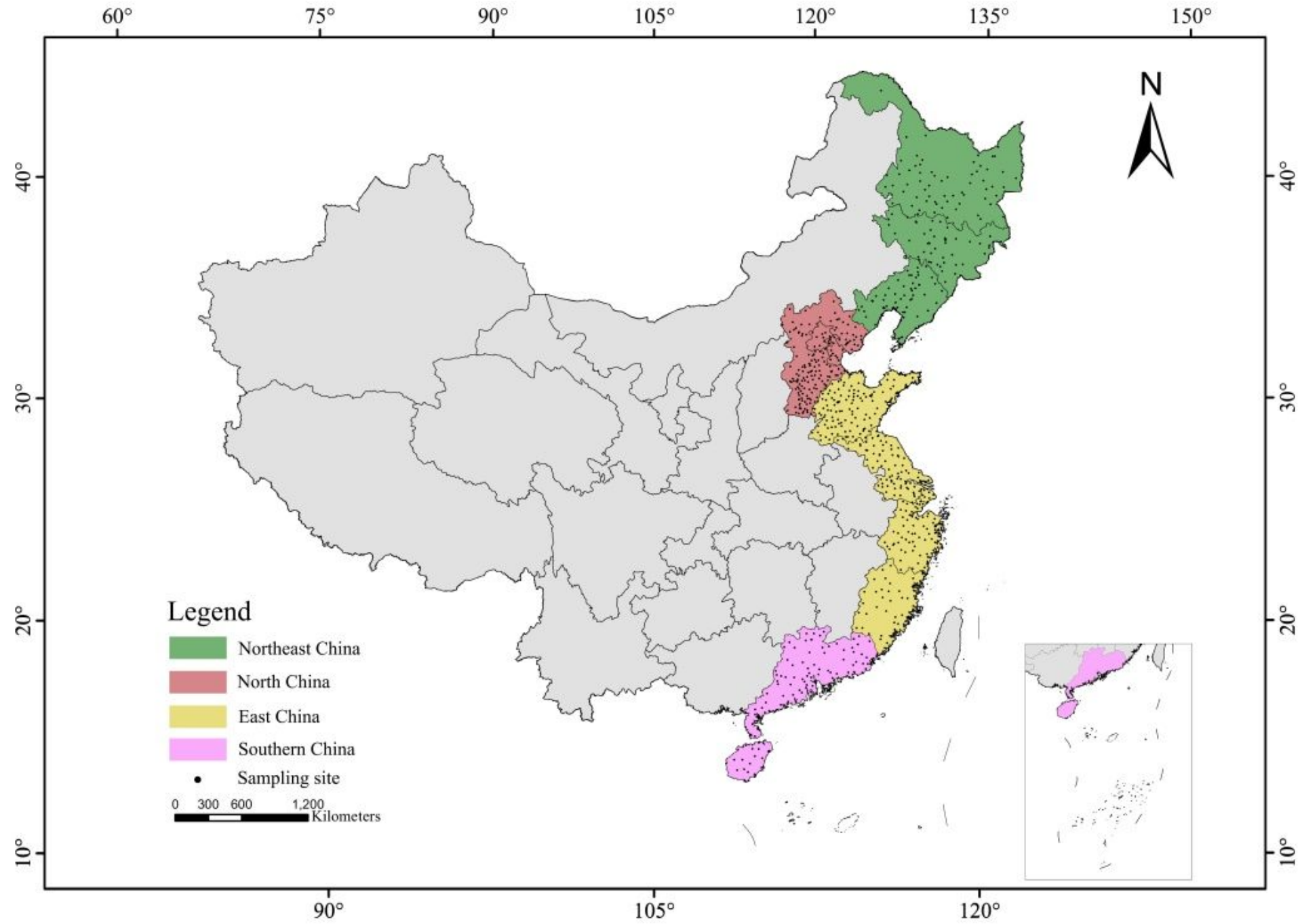

\section{Figure 1}

Schematic diagram of the study area and distribution of sample points Note: The designations employed and the presentation of the material on this map do not imply the expression of any opinion whatsoever on the part of Research Square concerning the legal status of any country, territory, city or area or of its authorities, or concerning the delimitation of its frontiers or boundaries. This map has been provided by the authors. 


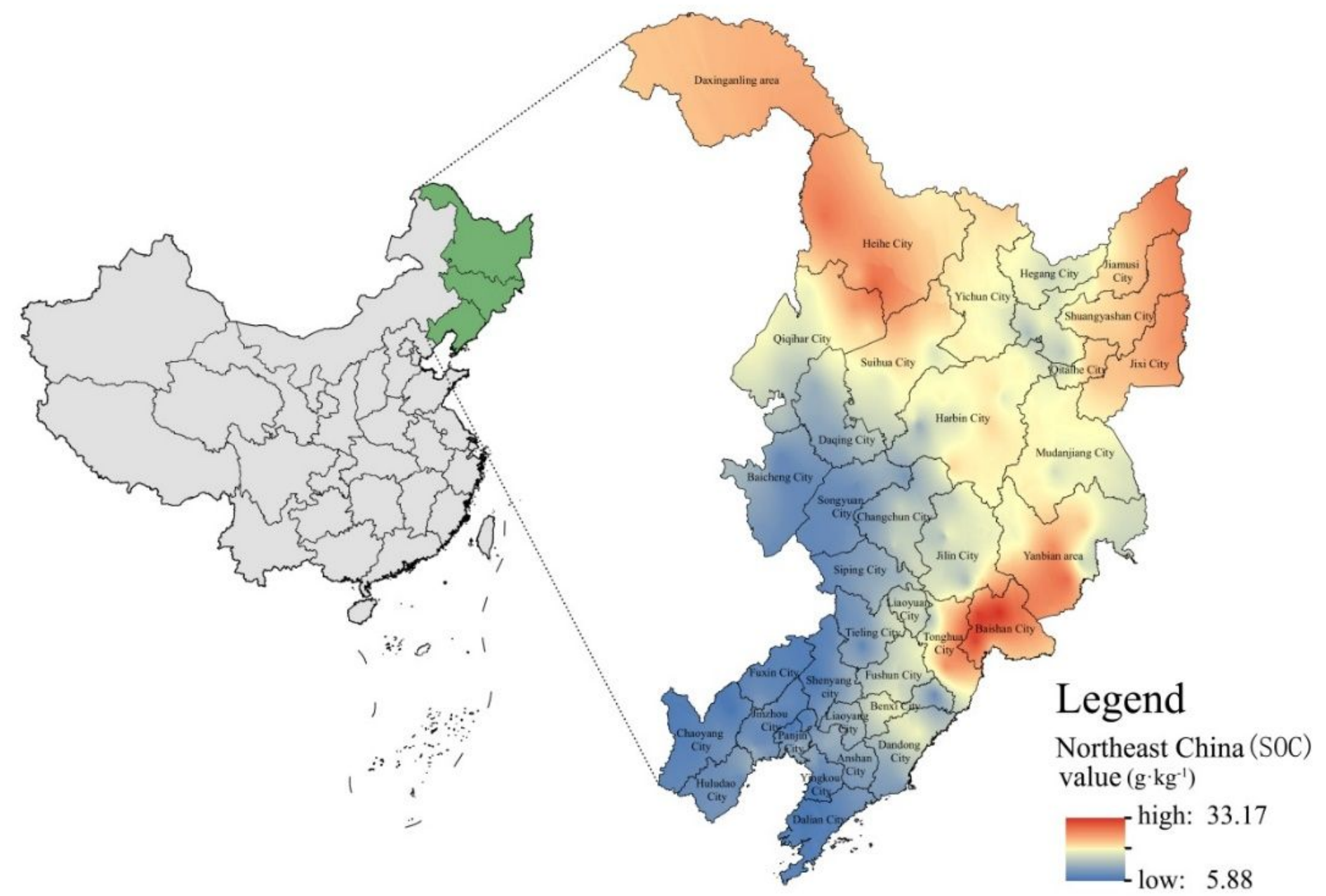

Figure 2

Distribution of SOC Northeast China Note: The designations employed and the presentation of the material on this map do not imply the expression of any opinion whatsoever on the part of Research Square concerning the legal status of any country, territory, city or area or of its authorities, or concerning the delimitation of its frontiers or boundaries. This map has been provided by the authors. 


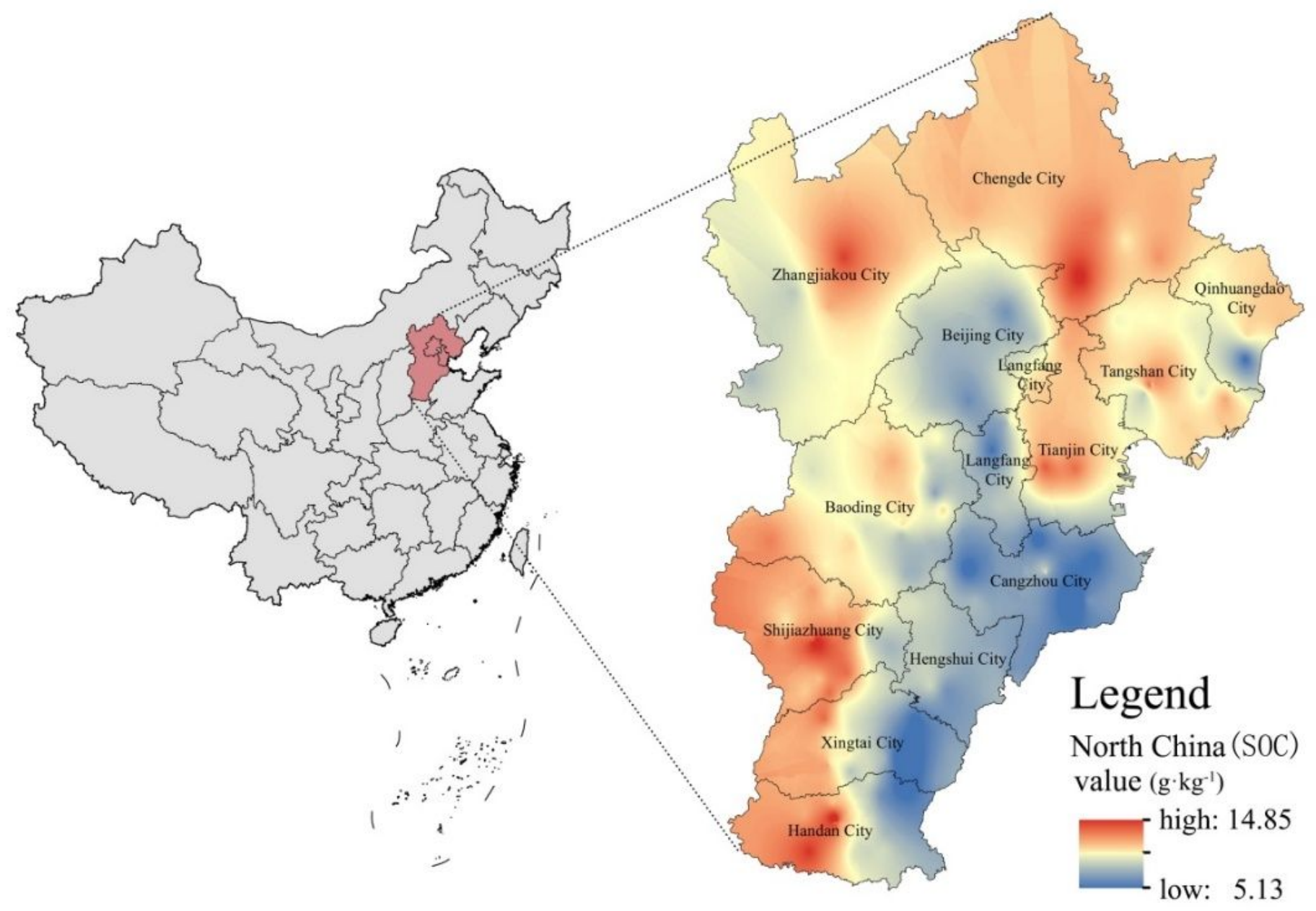

Figure 3

Distribution of SOC in North China Note: The designations employed and the presentation of the material on this map do not imply the expression of any opinion whatsoever on the part of Research Square concerning the legal status of any country, territory, city or area or of its authorities, or concerning the delimitation of its frontiers or boundaries. This map has been provided by the authors. 


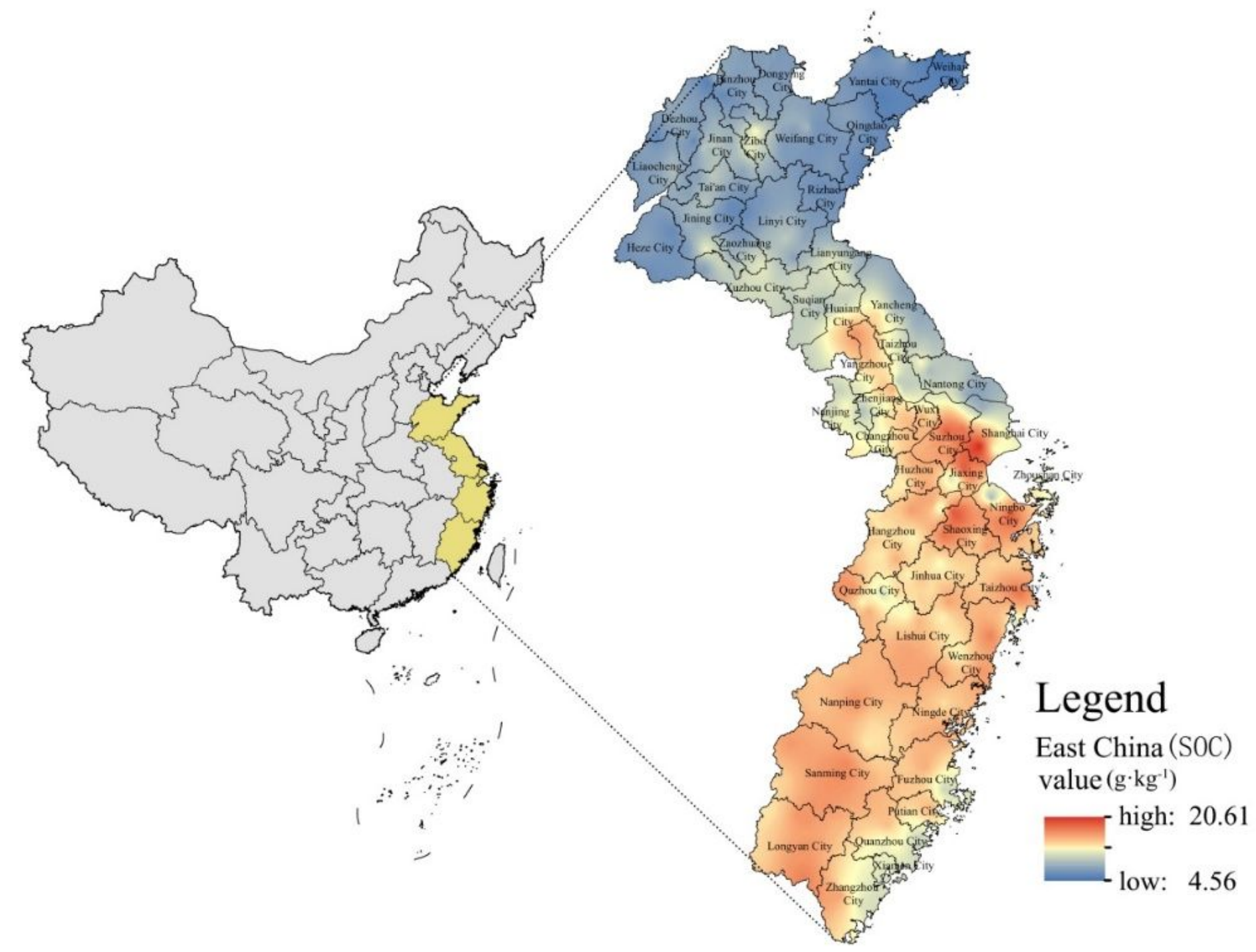

Figure 4

Distribution of SOC in East China Note: The designations employed and the presentation of the material on this map do not imply the expression of any opinion whatsoever on the part of Research Square concerning the legal status of any country, territory, city or area or of its authorities, or concerning the delimitation of its frontiers or boundaries. This map has been provided by the authors. 


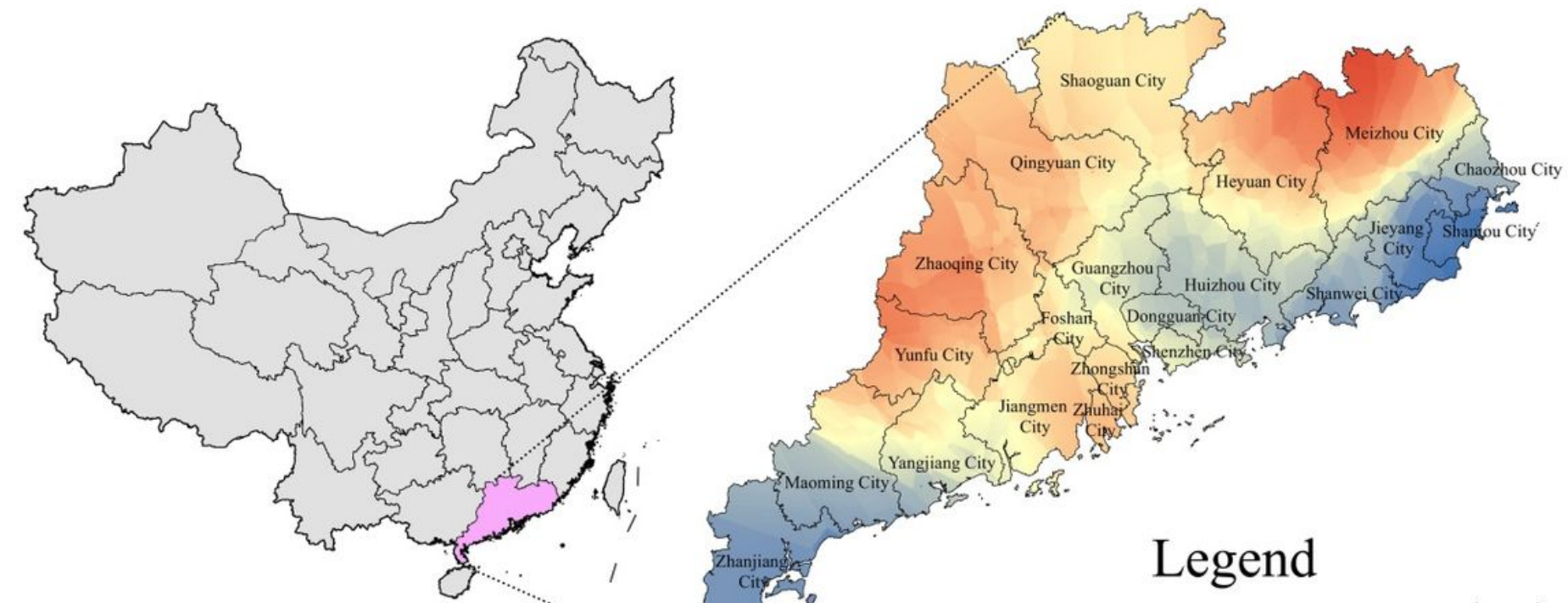

Guangdong province (SOC) value $\left(\mathrm{g} \cdot \mathrm{kg}^{-1}\right)$
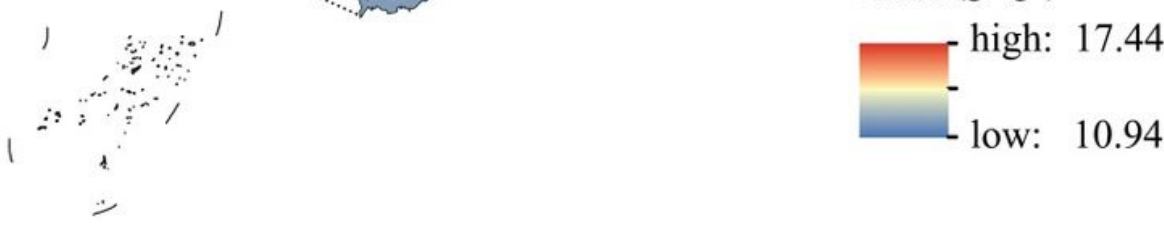

Figure 5

Distribution of SOC in Guangdong Province Note: The designations employed and the presentation of the material on this map do not imply the expression of any opinion whatsoever on the part of Research Square concerning the legal status of any country, territory, city or area or of its authorities, or concerning the delimitation of its frontiers or boundaries. This map has been provided by the authors. 


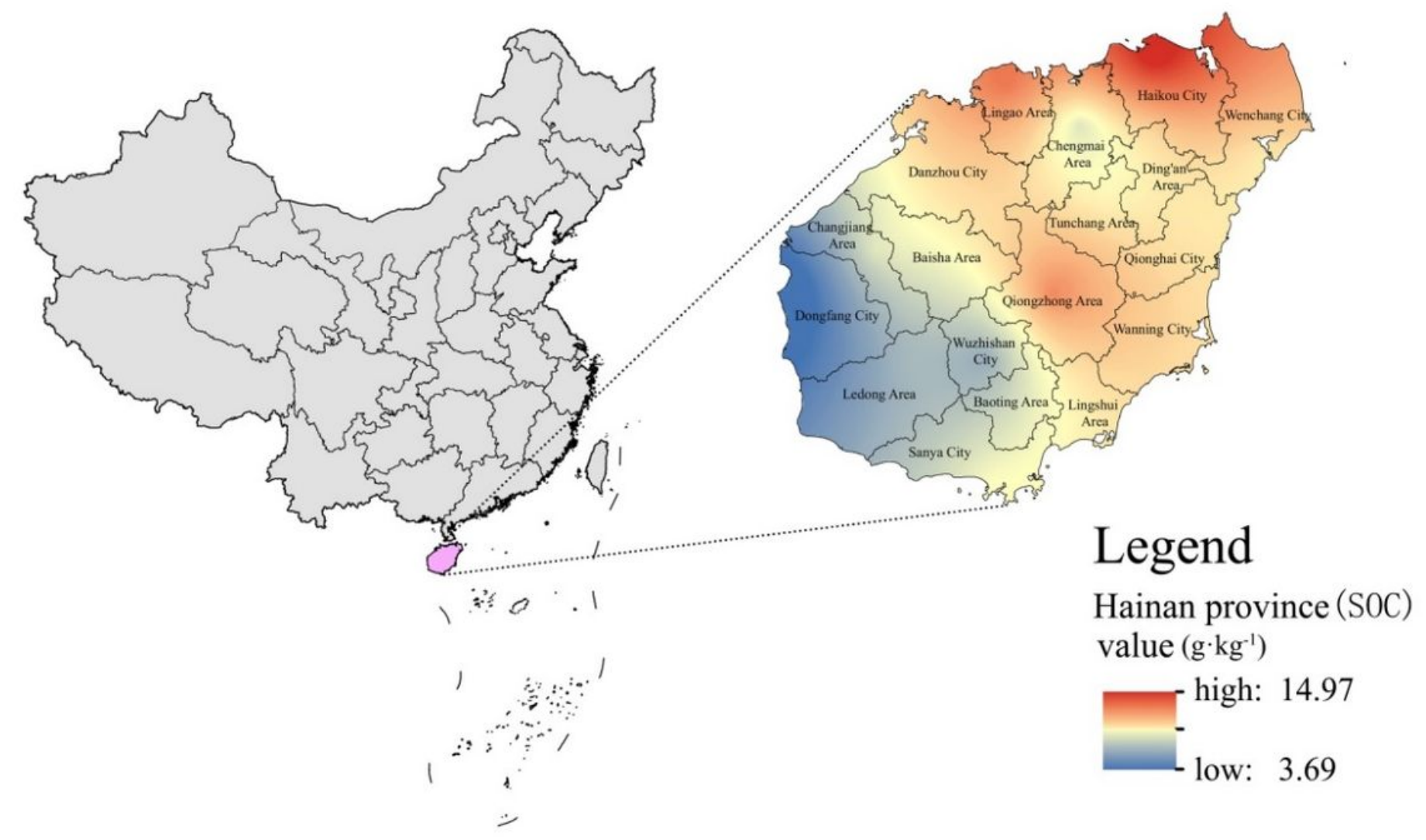

Figure 6

Distribution of SOC in Guangdong Province Note: The designations employed and the presentation of the material on this map do not imply the expression of any opinion whatsoever on the part of Research Square concerning the legal status of any country, territory, city or area or of its authorities, or concerning the delimitation of its frontiers or boundaries. This map has been provided by the authors. 


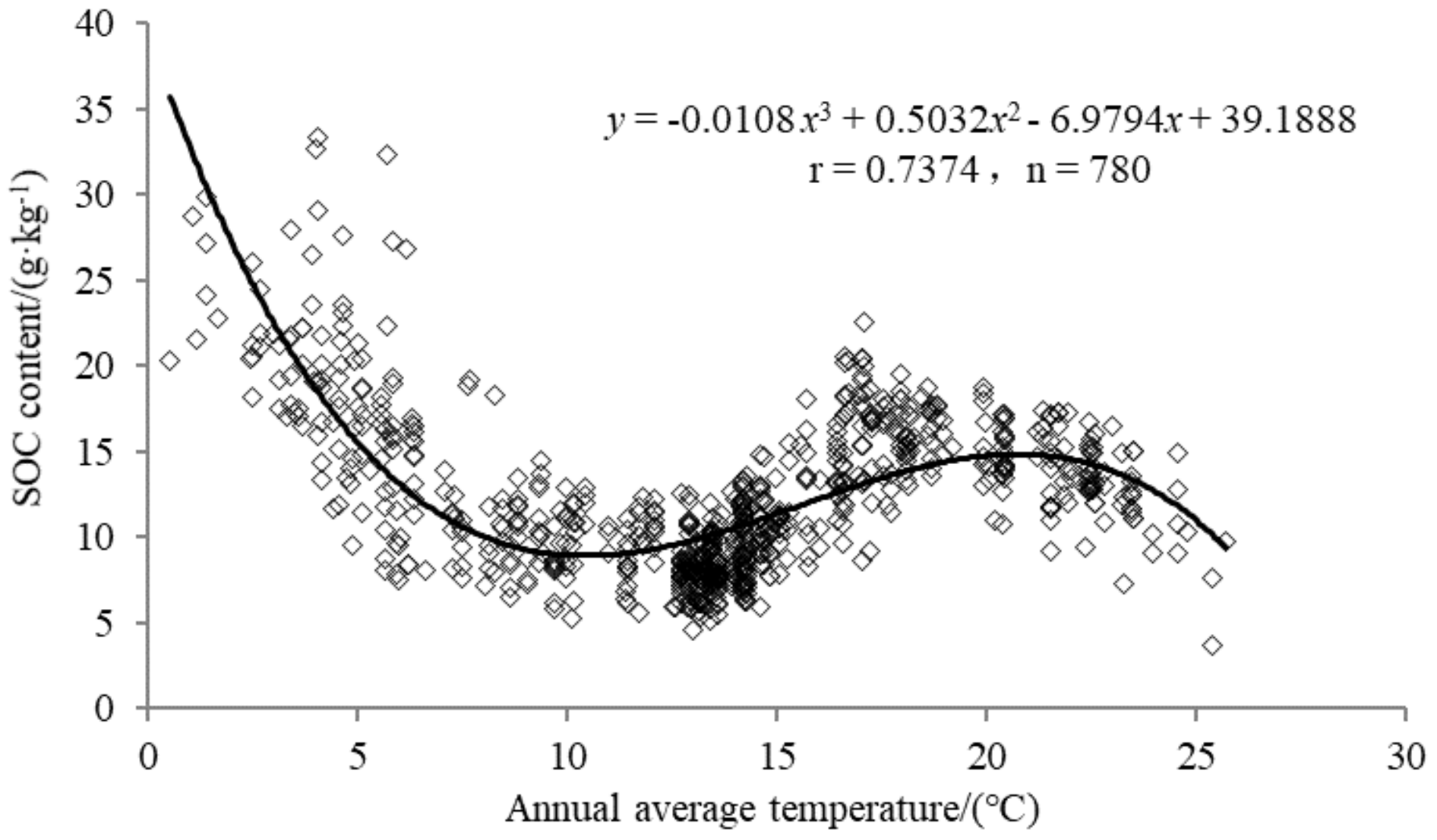

Figure 7

Relationship between SOC and annual average temperature $(n=883)$ 


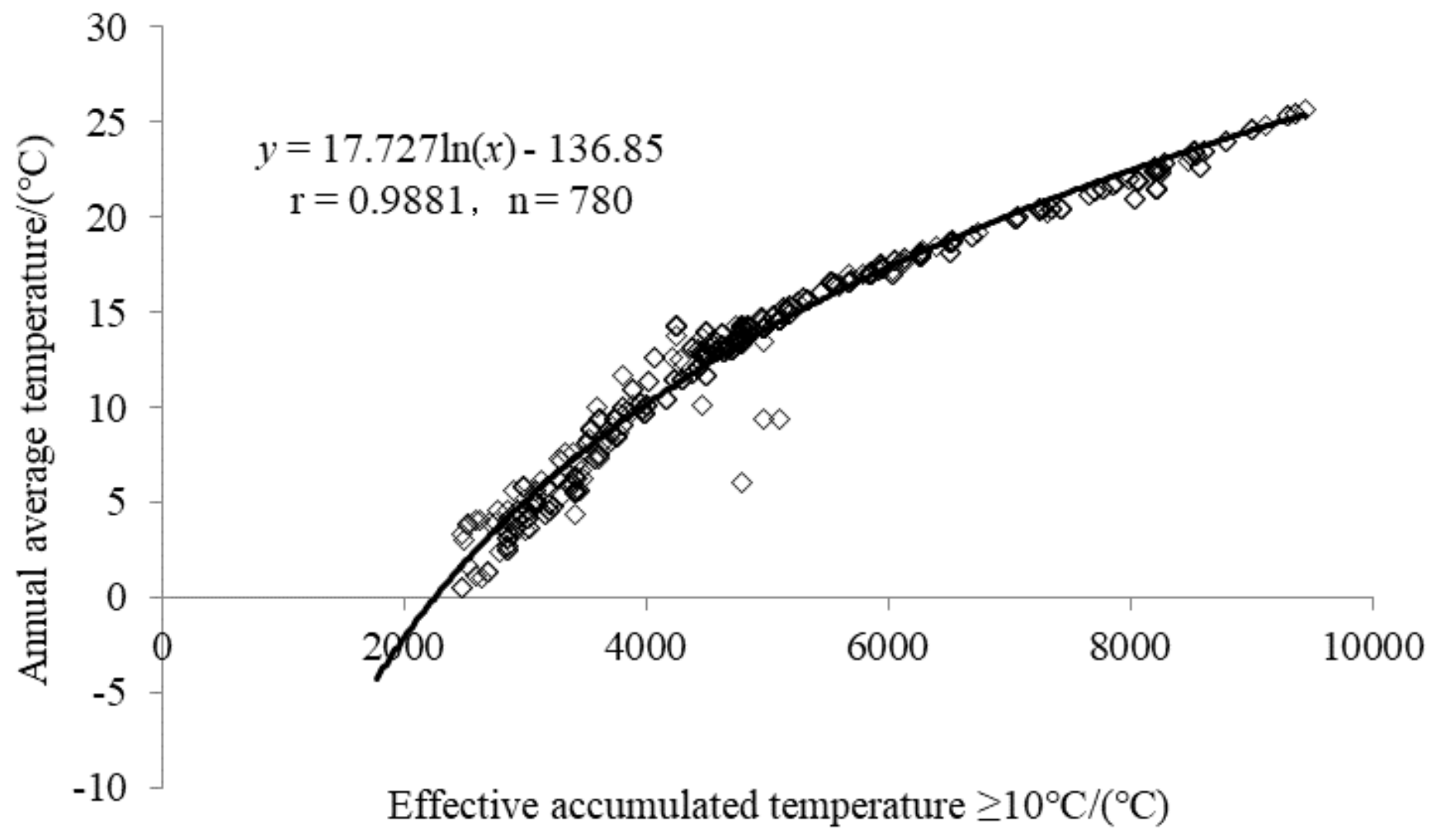

Figure 8

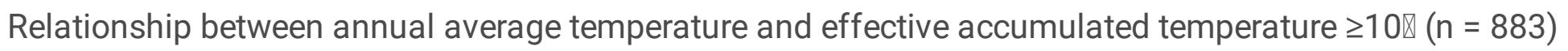

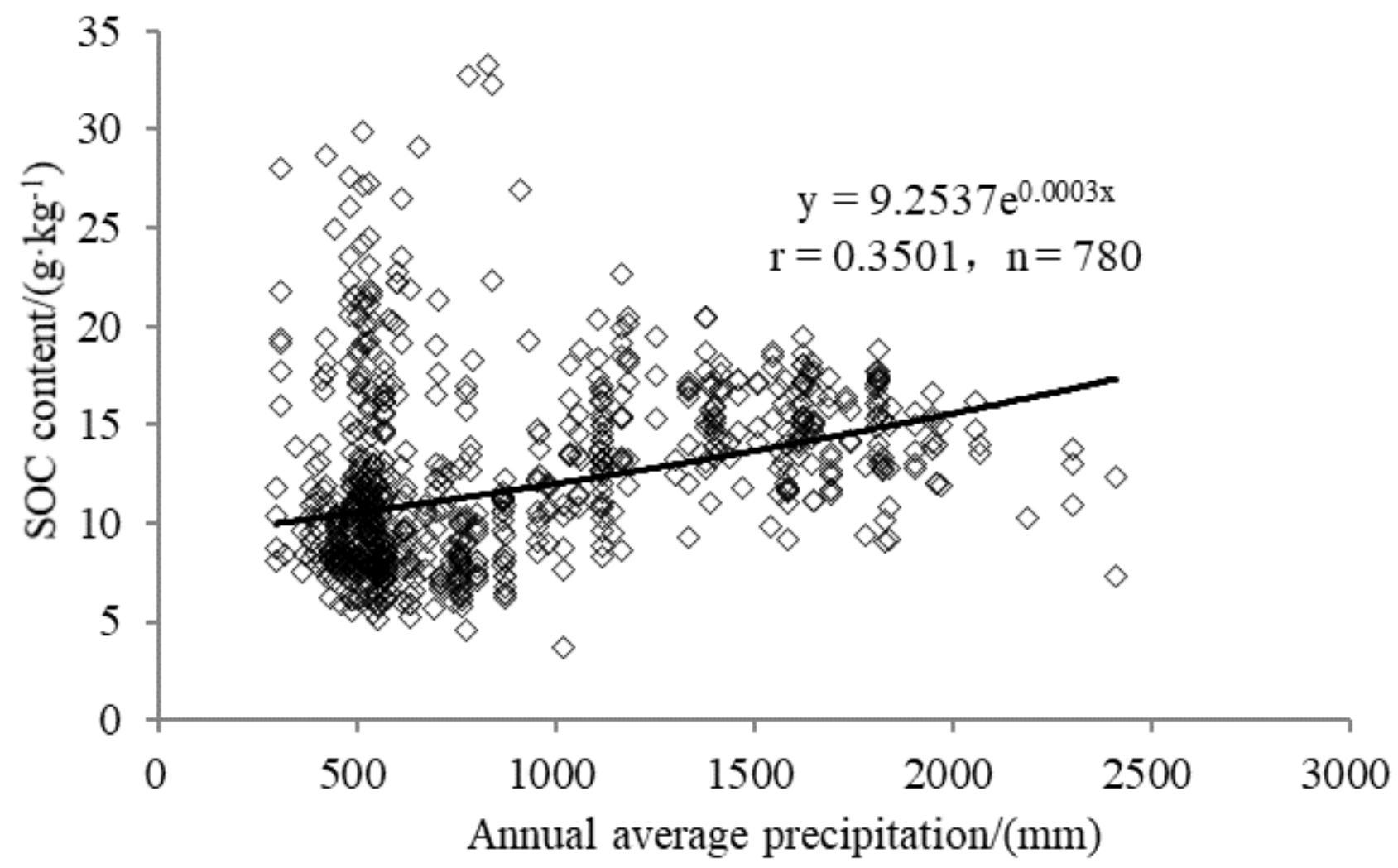


Figure 9

Relationship between SOC content and annual average precipitation $(n=780)$

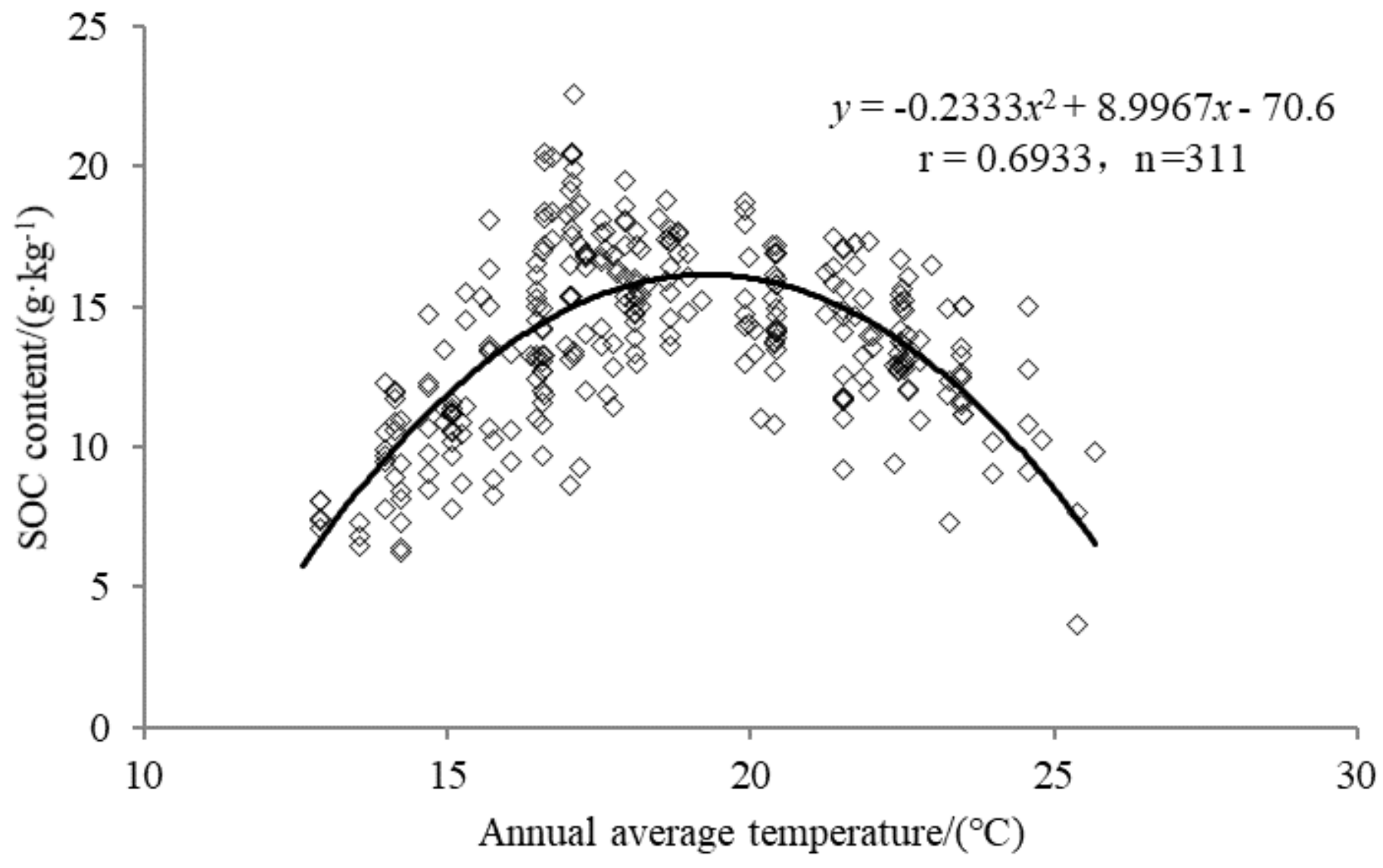

Figure 10

Relationship between SOC content and annual average temperature in the region with annual precipitation $>800 \mathrm{~mm}(\mathrm{n}=311)$ 


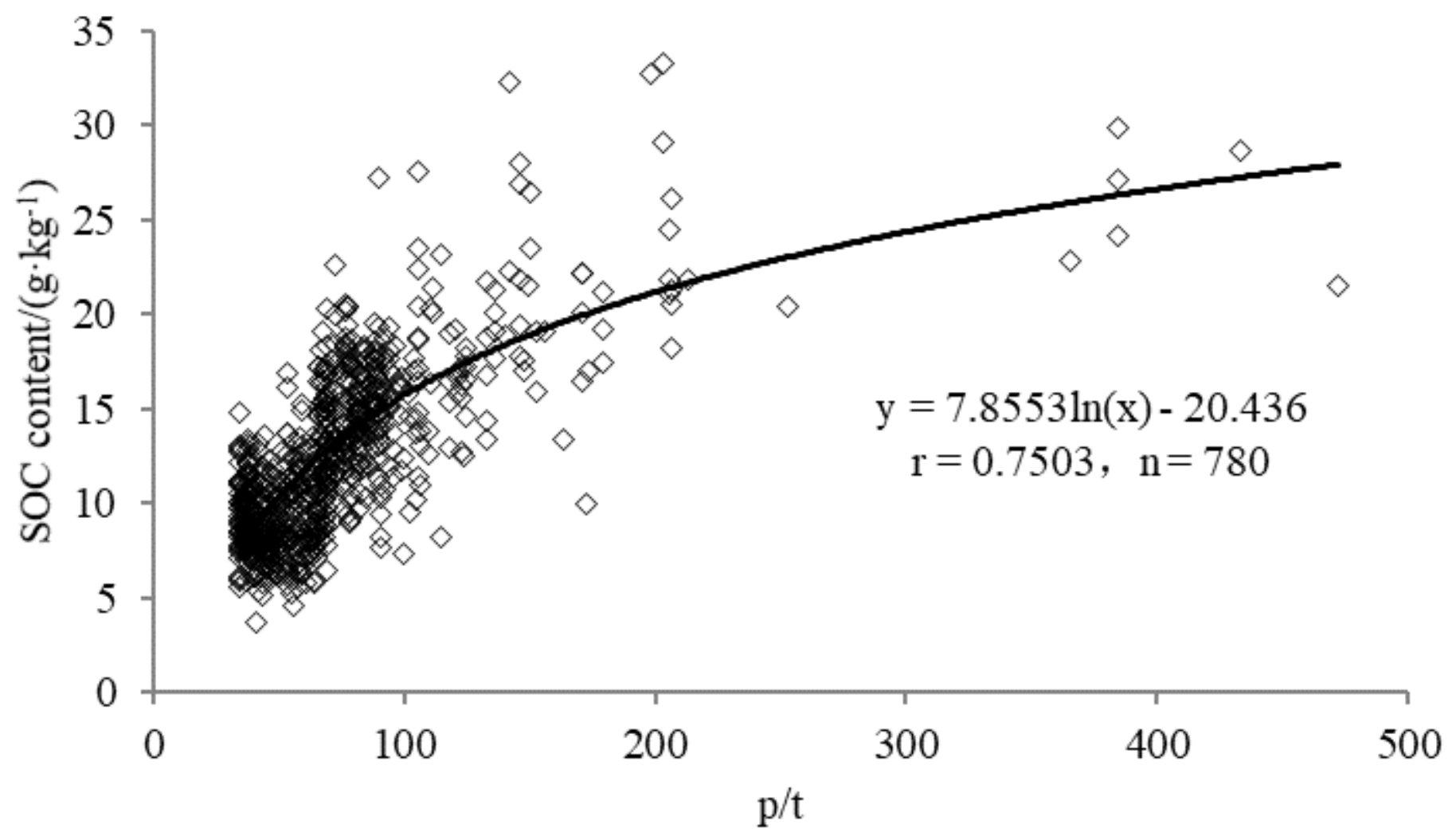

Figure 11

Relationship between SOC content and p/t $(n=780)$

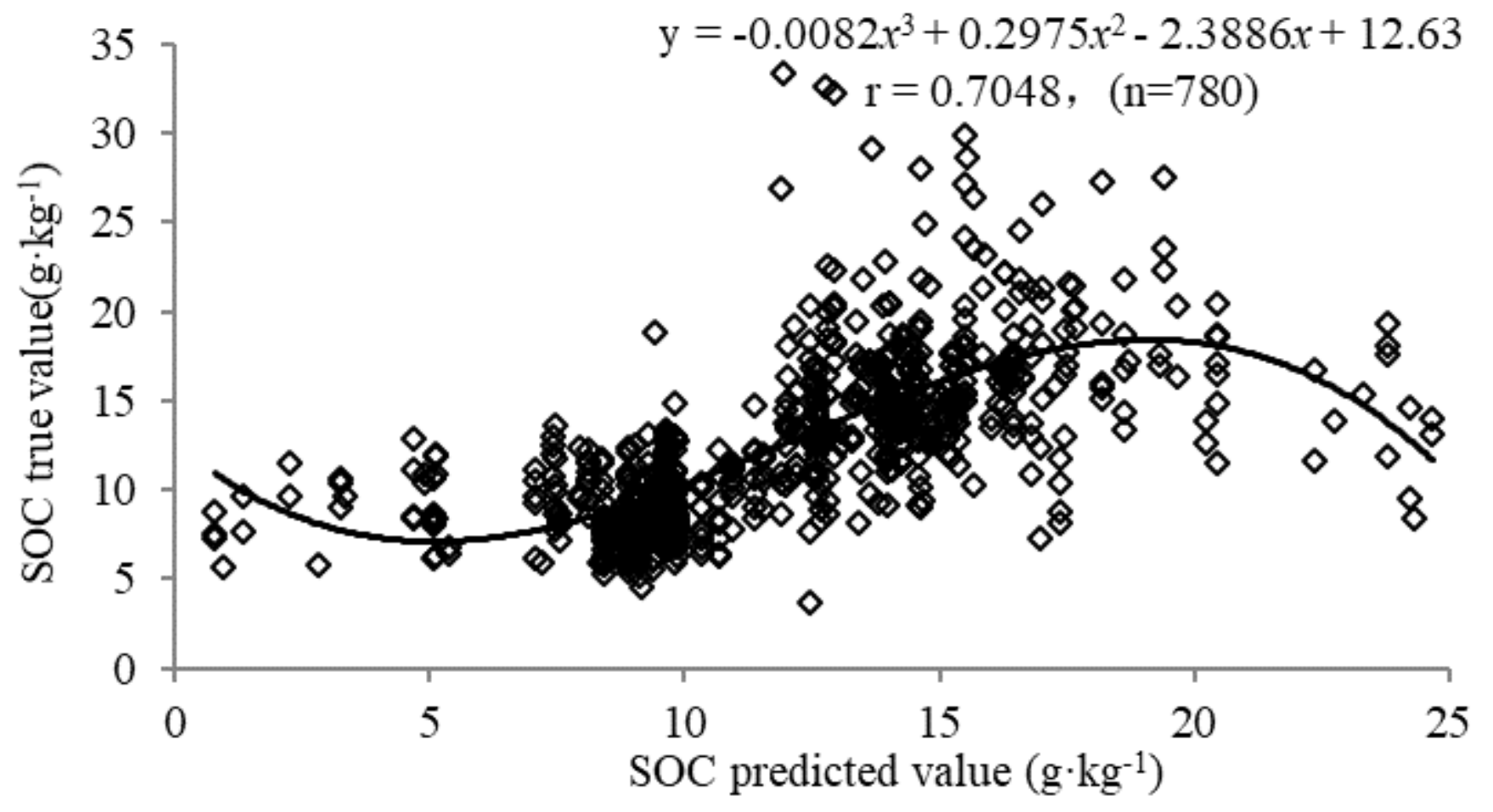

Figure 12 
Comparison of SOC predicted value and real value $(n=780)$ 